\title{
Intercomparison study and optical asphericity measurements of small ice particles in the CERN CLOUD experiment
}

\author{
Leonid Nichman ${ }^{1, a, b}$, Emma Järvinen ${ }^{2}$, James Dorsey ${ }^{1,3}$, Paul Connolly ${ }^{1}$, Jonathan Duplissy ${ }^{4}$, Claudia Fuchs ${ }^{5}$, \\ Karoliina Ignatius $^{6}$, Kamalika Sengupta ${ }^{7}$, Frank Stratmann ${ }^{6}$, Ottmar Möhler ${ }^{2}$, Martin Schnaiter ${ }^{2}$, and \\ Martin Gallagher ${ }^{1}$ \\ ${ }^{1}$ School of Earth, Atmospheric and Environmental Sciences, University of Manchester, Manchester M13 9PL, UK \\ ${ }^{2}$ Institute of Meteorology and Climate Research, Karlsruhe Institute of Technology, P.O. Box 3640, 76021, Germany \\ ${ }^{3}$ National Centre for Atmospheric Science, Manchester, UK \\ ${ }^{4}$ Department of Physics, P.O. Box 64, 00014 University of Helsinki, Helsinki, Finland \\ ${ }^{5}$ Laboratory of Atmospheric Chemistry, Paul Scherrer Institute, Villigen, Switzerland \\ ${ }^{6}$ Leibniz Institute for Tropospheric Research (TROPOS), 04318 Leipzig, Germany \\ ${ }^{7}$ University of Leeds, School of Earth and Environment, Leeds LS2-9JT, UK \\ ${ }^{a}$ now at: Department of Chemistry, Boston College, Chestnut Hill, MA, USA \\ bow at: Aerodyne Research, Inc, Billerica, MA, USA
}

Correspondence to: Leonid Nichman (leonid.nichman@manchester.ac.uk)

Received: 17 June 2016 - Discussion started: 3 August 2016

Revised: 7 July 2017 - Accepted: 28 July 2017 - Published: 4 September 2017

\begin{abstract}
Optical probes are frequently used for the detection of microphysical cloud particle properties such as liquid and ice phase, size and morphology. These properties can eventually influence the angular light scattering properties of cirrus clouds as well as the growth and accretion mechanisms of single cloud particles. In this study we compare four commonly used optical probes to examine their response to small cloud particles of different phase and asphericity. Cloud simulation experiments were conducted at the Cosmics Leaving OUtdoor Droplets (CLOUD) chamber at European Organisation for Nuclear Research (CERN). The chamber was operated in a series of multi-step adiabatic expansions to produce growth and sublimation of ice particles at super- and subsaturated ice conditions and for initial temperatures of $-30,-40$ and $-50^{\circ} \mathrm{C}$. The experiments were performed for ice cloud formation via homogeneous ice nucleation. We report the optical observations of small ice particles in deep convection and in situ cirrus simulations. Ice crystal asphericity deduced from measurements of spatially resolved single particle light scattering patterns by the Particle Phase Discriminator mark 2 (PPD-2K, Karlsruhe edition) were compared with Cloud and Aerosol Spectrometer with Polarisation (CASPOL) measurements and image roundness
\end{abstract}

captured by the 3 View Cloud Particle Imager (3V-CPI). Averaged path light scattering properties of the simulated ice clouds were measured using the Scattering Intensity Measurements for the Optical detectioN of icE (SIMONE) and single particle scattering properties were measured by the CASPOL.

We show the ambiguity of several optical measurements in ice fraction determination of homogeneously frozen ice in the case where sublimating quasi-spherical ice particles are present. Moreover, most of the instruments have difficulties of producing reliable ice fraction if small aspherical ice particles are present, and all of the instruments cannot separate perfectly spherical ice particles from supercooled droplets. Correlation analysis of bulk averaged path depolarisation measurements and single particle measurements of these clouds showed higher $R^{2}$ values at high concentrations and small diameters, but these results require further confirmation. We find that none of these instruments were able to determine unambiguously the phase of the small particles. These results have implications for the interpretation of atmospheric measurements and parametrisations for modelling, particularly for low particle number concentration clouds. 


\section{Introduction}

One of the first attempts to distinguish ice particles from water drops in the atmosphere was made almost 70 years ago in the Thunderstorm project (Byers and Braham, 1948), during which it was noted that ice particles produce a different sound compared to water drops when they impact the canopy of the aircraft. Since then, there have been many developments of airborne instruments for the measurement of cloud microphysical properties. Wendisch and Brenguier (2013) compiled a comprehensive list covering 48 different instruments, many of which are historical, but recently there have been several new developments, e.g. Abdelmonem et al. (2016) and Baumgardner et al. (2014, 2017). Many of the current techniques, however, are technological improvements on previous instruments originally developed and flown in the 1970s. An ongoing problem is the in situ measurement of concentrations of small ice crystals $<100 \mu \mathrm{m}$ in size. Accurate measurements of ice crystal size distributions are necessary for evaluation of ice cloud radiative effects, development and evaluation of remote sensing algorithms, evaluation of aerosol impacts and ultimately correct representation of ice clouds in climate models (Jensen et al., 2009).

This microphysical information is also important in research of early ice formation, when initial ice particles in low concentrations push the sampling volume limits of many instruments (Johnson et al., 2014). Optical methods are preferably employed both for remote sensing of clouds and for in situ single particle measurements. High-resolution measurement of the forward-scattered light pattern is compared here with the mean scattering intensity from ensemble measurements, where shape information (i.e. asphericity) is averaged due to different orientations of the particles in the measuring volume (Sachweh et al., 1999).

Droplet concentration in clouds normally varies between several tens and hundreds of cubic centimetres, while typical ice crystal concentration is normally a few particles per litre but can reach $\sim 100 \mathrm{~L}^{-1}$ in some clouds (Wallace and Hobbs, 2006). The diameter of single droplet or ice crystal is normally in the supermicron range and can reach several hundred micrometres. The initial shape of ice particles may be indistinguishable from water droplets. Optically ambiguous shapes of liquid and solid cloud particles such as water, frozen droplets and quasi-spherical ice (Gayet et al., 2012; Järvinen et al., 2016c) may be detected simultaneously in the troposphere. Some of these particle phases coexist for long periods of time, e.g. in long-lived mixed-phase stratiform layers (Korolev and Isaac, 2003a). The resolution of most optical probes, coupled with coincidence problems, prevents a clear determination of particle shape for particle sizes smaller than $100 \mu \mathrm{m}$ in such clouds. In glaciated clouds, Cober et al. (2001) applied geometric formulas to 2-D images, identifying between 5 and $40 \%$ of them as circular. Spherical particles were observed in large numbers by Korolev and
Isaac (2003b) even in clouds subsaturated with respect to water. Moreover, Jensen et al. (2013) report vertically thin cirrus layers with high ice concentration (up to $10000 \mathrm{~L}^{-1}$ ) of small ice crystals, which can only be produced by homogeneous freezing of an abundant population of aqueous aerosols. As a result of this shape ambiguity and low resolution of small sizes, our fundamental knowledge of small cloud particle microphysics is still far from complete.

Large supercooled water droplets up to $5 \mathrm{~mm}$ in diameter exist only at warmer ambient temperatures, but smaller cloud droplets may frequently exist in a supercooled state down to $-20^{\circ} \mathrm{C}$ and less frequently as low as the homogeneous freezing level (Elliott and Smith, 2015; Rosenfeld and Woodley, 2000). Furthermore, very small supercooled water droplets may stay in a metastable liquid condition down to $-40^{\circ} \mathrm{C}$ (Korolev and Isaac, 2003a). Pilots often reported deviating around convective clouds due to the danger of ice accretion of supercooled droplets (Jeanne et al., 2006). Therefore, an inaccurate classification of spherical shapes may directly affect the routes and costs of commercial flights (Gallagher et al., 2016).

Frozen droplets are an important feature of mid-latitude anvil cirrus. In fact, frozen droplets and frozen droplet agglomerates are also a dominant particle type in higher anvil outflow clouds (Stith et al., 2014; Järvinen et al., 2016c). Frozen droplets could also be responsible for first ice initiation in deep convective clouds (Taylor et al., 2016). Although frozen droplets are frequently measured, our understanding of the microphysical and optical properties of these quasi-spherical ice particles is somewhat vague. The process by which frozen droplets are formed can play an important role in their morphology. Microscopic structures, like surface roughness, as well as detailed information on the aspect ratios of the frozen droplets found in clouds are key variables required to determine the optical parameters that are included in the modelling and prediction of the climate effect of these cloud systems.

In addition, quasi-spherical ice shapes are common in cirrus. Luebke et al. (2016) and Garrett et al. (2005) report the presence of many quasi-spherical ice particles in cirrus, especially at the smaller sizes. Quasi-spherical ice prevails also in contrails at low temperatures below about $-55^{\circ} \mathrm{C}$. In the core of the contrail, high crystal concentrations reduce the vapour density to saturation, causing the ice particle to retain a nearly spherical shape (Lawson et al., 1998; Lynch, 2001). Contrail cirrus cover is small compared to natural cirrus; nonetheless, they still have a climatic impact with the constant increase in jet aircraft traffic (Stordal et al., 2005; Irvine and Shine, 2015).

Cloud particles measurements on aircraft campaigns inherently suffer from limited spatial coverage and limited instrument sampling volumes. Cirrus clouds do not have an obvious formation stage, and therefore it is not possible to reliably position a research aircraft in their development stage (Lawson et al., 2006a). Remote sensing provides av- 
eraged features but is insensitive in cases of subvisual or contrail cirrus. Conversely, chamber experiments provide a well-controlled and pristine environment for simulations and instrumental comparison, although the role of the ice nucleation process in the atmosphere may change with time through the life cycle of a convective cloud, for example, and is strongly influenced by the environmental airflow (Heymsfield et al., 2005; Zhang and Harrington, 2015).

Our chamber campaign investigating the homogeneous freezing process relevant to the upper region of deep convective clouds and in situ formed cirrus in pristine environments was conducted at the European Organisation for Nuclear Research (CERN) in 2013, hereafter referred to as CLOUD 8. The goal of the experiments presented here was to complement and extend the results previously obtained in the Aerosol Interaction and Dynamics in the Atmosphere (AIDA) chamber with similar instruments (Järvinen et al., 2016c; Schnaiter et al., 2016) such as observation of morphological features and confirmation of a possible pathway for quasi-spherical ice formation which affects growth and sedimentation mechanisms of ice in clouds. Additionally, a comparative analysis of four optical probes is reported in this paper to provide clarification of optical measurements in several respects: single particle versus averaged path optical measurements, polarisation measurements versus depolarisation and asphericity derivation. These were addressed using measurements from current instrumentation techniques for both in situ and path averaged chamber studies and include scattering patterns of the near-forward-scattered light measured by the Particle Phase Discriminator mark 2 instrument (PPD-2K, Karlsruhe edition), single particle polarisation properties measured by the Cloud and Aerosol Spectrometer with Polarisation (CASPOL, DMT-NCAS version) and image analysis provided by the 3 View Cloud Particle Imager instrument (3V-CPI, SPEC Inc.). Data products from such measurement techniques are often used to prescribe particle asphericity, which is then often used to determine the ice number and mass fraction in a cloud, assuming that the "ice" fraction is equivalent to an aspherical fraction. This practice is tested in our experiments.

\section{Methodology}

\subsection{The CLOUD chamber}

The chamber facility at CERN has been described in detail by Duplissy et al. (2016), Kirkby et al. (2011) and Guida et al. (2013). The expansion system installed at the Cosmics Leaving OUtdoor Droplets (CLOUD) chamber allows production of relatively high cooling rates, above $5^{\circ} \mathrm{C} \mathrm{min}^{-1}$, compared to the AIDA chamber, where maximum cooling rate of $4^{\circ} \mathrm{C} \mathrm{min}^{-1}$ is typically achieved (Möhler et al., 2006; Järvinen et al., 2016c). Stronger cooling rates will activate a higher fraction of the aerosol by driving higher peak su- persaturation. Since the liquid water content that freezes does not vary with updraft strength, the freezing of more numerous droplets in the faster updrafts simply produces smaller ice particles. This is clearly shown by Ackerman et al. (2015), in which ice particle mass distributions in homogeneous freezing for stronger updrafts produce substantially smaller ice particles. Schnaiter et al. (2016) further showed that high ice particle growth rates also enhance the formation of small-scale complexity, such as ice particle surface roughness. Gayet et al. (2011) reported that in a deeply rough surface the mean free path length between two subsequent inclusions was equal to $15 \%$ of the diameter of the circle circumscribing the hexagonal facet of an ice crystal. Following the procedure suggested by Schnaiter et al. (2016), we have simulated similar conditions for the derivation of aspherical fractions and instrumental intercomparison in the CLOUD chamber (Fig. S1 in the Supplement), where ice particles are sequentially sublimated and then grown under different supersaturated conditions. This multi-step adiabatic expansion mechanism allows the regrowth of ice after sublimation as will be explained in the next section.

\subsection{Overview of the homogeneous freezing experiments}

In the cloud chamber experiments, we have simulated some of the homogeneous freezing processes taking place in the deep convective cloud systems, i.e. with updraft velocities up to $5 \mathrm{~m} \mathrm{~s}^{-1}$ with corresponding cooling rates up to $5.8^{\circ} \mathrm{C} \mathrm{min}^{-1}$. In the following sections we present the evolution of the ice particle shape upon freezing, sublimation and re-growth periods from selected representative individual experimental runs. Overall, all the results from repeated individual experiments agreed well with each other. A representative list of the conducted experiments can be found in Table 1. The technical description of the CLOUD chamber pressurisation, cloud condensation nuclei $(\mathrm{CCN})$ injection and expansion of the air volume in a multi-step regime is given in detail elsewhere (Nichman et al., 2016; Duplissy et al., 2016; Guida et al., 2012, 2013) and will be briefly described here.

Continuous attempts to find an accurate ice cloud classification have led to the suggestion of new definitions of liquid origin cirrus clouds and in situ generated cirrus clouds (Krämer et al., 2016; Luebke et al., 2016). The liquid origin cirrus class comprises those clouds where ice crystals are formed by homogeneous freezing of liquid drops lower in the atmosphere and which are then uplifted into the cirrus temperature range. In situ cirrus class clouds are those which may form in fast updrafts triggered by jet streams or lee waves. This class is characterized by high IWC and many small ice crystals. The formation mechanism in this case is insensitive to IN properties and dominated by homogeneous freezing. The expansion profiles used in the CLOUD chamber allow simulation of both these types of clouds. 
Table 1. List of experiments. CCN concentration measured with $\mathrm{CPC}$ at the beginning of each expansion. Cloud particle $\mathrm{d} N / \mathrm{d} l o g D_{\mathrm{p}}$ (water and ice) for the mean diameter is shown in the last column.

\begin{tabular}{lrrrrr}
\hline $\begin{array}{l}\text { Exp. } \\
\text { number }\end{array}$ & $\begin{array}{r}\mathrm{CCN} \text { conc. } \\
\left(\mathrm{cm}^{-3}\right)\end{array}$ & $\begin{array}{r}\text { Cooling rate } \\
\left({ }^{\circ} \mathrm{C} \mathrm{min}^{-1}\right)\end{array}$ & $\begin{array}{r}T \text { start } \\
\left({ }^{\circ} \mathrm{C}\right)\end{array}$ & $\begin{array}{r}\text { Mean diameter } \\
(\mu \mathrm{m})\end{array}$ & $\begin{array}{r}\mathrm{d} N / \mathrm{d} \log D_{\mathrm{p}} \\
\left(\mathrm{cm}^{-3}\right)\end{array}$ \\
\hline 1276.05 & 220 & -5.0 & -40 & 7.9 & 48.0 \\
1291.07 & 160 & -5.8 & -30 & 10.0 & 41.7 \\
1291.12 & 110 & -4.8 & -30 & 15.0 & 30.0 \\
1292.01 & 150 & -4.9 & -30 & 12.0 & 41.7 \\
1298.12 & 110 & -2.1 & -50 & 9.0 & 6.5 \\
1298.20 & 750 & -3.1 & -50 & 8.0 & 9.9 \\
\hline
\end{tabular}

The homogeneous freezing experiments commenced in a pressurised chamber volume, at $123.3 \mathrm{kPa}$, with a $\mathrm{CCN}$ injection. The sulfuric acid solution droplets, used as $\mathrm{CCN}$, were generated in a sulfuric acid generator consisting of heated sulfuric acid reservoir and airflow past the reservoir. A more detailed explanation of the generation method can be found in Wagner et al. (2008). By varying the duration of the sulfuric acid injection we controlled the number concentration of the sulfuric acid droplets, and by adjusting the temperature of the sulfuric acid reservoir and the airflow rate through the heated reservoir we controlled the mean size of the CCN particles.

The CLOUD chamber is surrounded by an insulated thermal housing, which allows precise regulation of the internal temperature with stability within $0.1^{\circ} \mathrm{C}$. Dias et al. (2017) found that larger temperature non-uniformities of up to around $\pm 1.0^{\circ} \mathrm{C}$ are present at the minimum temperature reached after an adiabatic expansion compared with operation under equilibrium conditions, in both radial and vertical directions. The turbulence induced by the expansion ensures complete mixing of the chamber during the expansion. Thermal non-uniformities in the radial direction subsequently decrease as the air reheats. The in situ temperature values used here were measured close to the centre of the chamber, and to the sampling plane of CASPOL (Fig. S1), at $1.2 \mathrm{~m}$ distance from the walls using a PT100 temperature sensor (Duplissy et al., 2016; Dias et al., 2017). For pressure monitoring in the chamber, we used the VEGABAR 53 process pressure transmitter (VEGA). The total humidity inside the chamber was measured by a fast chilled-mirror frost-point hygrometer (MBW, model 373LX). The relative humidity $(\mathrm{RH})$ with respect to water and ice (see the example in Fig. 1a) was calculated from dew and frost points using water and ice saturation vapour pressure at the measured temperature (Buck, 1996) with correction for the contribution from the condensed phase due to a higher temperature in the MBW sampling line.

At the beginning of most experiments, we generated low concentrations $\left(\sim 100 \mathrm{~cm}^{-3}\right)$ of sulfuric acid aerosol. Concentrations were measured with a condensation particle counter (CPC; TSI model 3010). At these concentrations, all

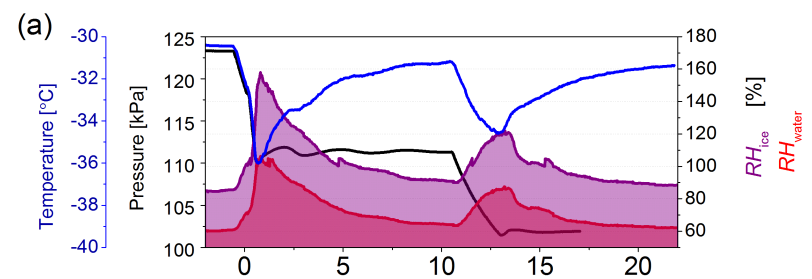

(b)

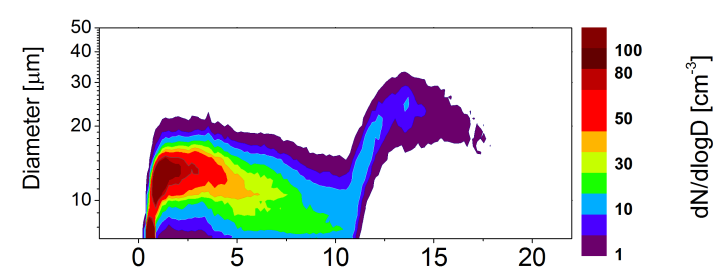

(c)

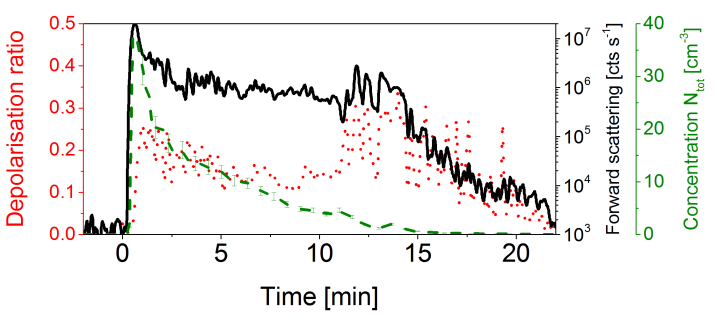

Figure 1. Homogeneous ice nucleation and regrowth experiment no. $1292.01\left(-30^{\circ} \mathrm{C}\right)$. (a) The temporal development of pressure, temperature and $\mathrm{RH}$ calculated from the chilled mirror hygrometer (MBW 373LX) and thermocouples measurements at the mid-plane of the chamber. The lowest temperature measured after the expansion was $\sim-37^{\circ} \mathrm{C}$ at a lower section of the chamber (Fig. A2), but lower temperatures are probable at the bottom of the chamber due to the temperature gradient. $\mathrm{RH}$ with respect to ice is shown in purple and with respect to water $\left(\mathrm{RH}_{\mathrm{water}}\right)$ in red. Cloud forms at $t=0 \mathrm{~min}$. At the mid-plain $\mathrm{RH}_{\text {ice-max }} \sim 158 \%$ lasted for $\sim 20 \mathrm{~s}$. (b) The particle number size distribution measured with PPD-2K. (c) SIMONE measurement of the forward scattering intensity (counts s ${ }^{-1}$, black solid line) and depolarisation ratio (red dotted line) together with the total number concentration $\left(N_{\text {tot }} \mathrm{cm}^{-3}\right)$ measured by the PPD-2K (green dashed line). 
seed aerosols will act as $\mathrm{CCN}$ at almost the same time and further homogeneous nucleation and growth of the ice crystals would occur upon further expansion cooling. All the experiments were initiated slightly below ice saturated conditions at temperatures near $-30,-40$ and $-50{ }^{\circ} \mathrm{C}$ (Figs. 1a, A1 in the Appendix). In the experiments starting at $-30^{\circ} \mathrm{C}$ we cooled the chamber air by expanding the volume until supercooled liquid droplets were formed. A fraction of the droplets were grown by further cooling until ice started to form by homogeneous freezing of the supercooled water droplets. The ice particles then grew until the expansion was stopped and the formed ice crystals started to sublimate under ice subsaturated conditions, induced by an increase in temperature due to the heat flow from the warm chamber walls. The lowest measured temperature reached at the bottom section of the chamber is $\sim-37^{\circ} \mathrm{C}$. After the end of the expansion, the temperature of the chamber is maintained for several tens of seconds until the reheating process takes place. The upper section of the chamber is warmer than the average temperature by $\sim 1.5^{\circ} \mathrm{C}$ (Fig. A2). A second step in the expansion profile then allowed the regrowth of the sublimating particles.

The experiments at $-50^{\circ} \mathrm{C}$ were started similarly by cooling the chamber volume until the first ice particles were formed by deposition nucleation. After the first ice particles were detected and had grown in size (see Table 1), we proceeded to the next step of the multistep expansion profile as discussed above.

\subsection{Cloud probes}

\subsubsection{PPD-2K}

The PPD-2K instrument used here has a light source consisting of a frequency-doubled Nd:YAG laser which emits $100 \mathrm{~mW}$ at a wavelength of $532 \mathrm{~nm}$. The sensitive areas of the trigger detector and camera are identical $\left(\sim 2.5 \mathrm{~mm}^{2}\right)$. The trigger count rate and pulse intensities are used to derive particle number concentrations and particle number size distributions. Reduction of the sample volume due to electronic dead time is corrected according to Vochezer et al. (2016). The classification of cloud particles by the PPD-2K is based on a spatial analysis of high-resolution intensity patterns of single particles in the 5 to $26^{\circ}$ forward scattering angular range. In the scattering patterns of (spherical) droplets we normally observe concentric rings at angular positions corresponding to the maxima intensities predicted by Mie theory. The sampling flow of the instrument was set to $5 \mathrm{~L} \mathrm{~min}^{-1}$ with a sheath flow of $2 \mathrm{~L} \mathrm{~min}^{-1}$. Due to detection limitation in small ice spectrometers currently, major coincidence errors at even moderate concentrations, particularly in mixedphase clouds, can become an issue (e.g. Hirst et al., 2001; Cotton et al., 2010; Vochezer et al., 2016). However, based on the total particle concentrations expected in our chamber experiments the calculated probability for coincidence was negligible, $<1 \%$ in most cases (Eq. 1c in Vochezer et al., 2016).

We used computerised discrimination of images with concentric rings from images without the rings based on variance calculation of the image pixels along the polar integrated azimuthal intensity profiles (Vochezer et al., 2016; Järvinen et al., 2016c). Aspherical fractions were determined by applying a threshold variance value of $10^{-5}$. This threshold is confirmed based on the visual inspection of diffraction patterns of ice and droplets in all chamber experiments. Images with low variance, corresponding to concentric rings, were classified as spherical (e.g. droplets). Similarly, in the case of ice particles with mean variance below this value the particles were classified as spherical. Ice habits, e.g. columns and plates, have characteristic scattering patterns which allow classification of the detected particles. More technical details are described in Vochezer et al. (2016).

\subsubsection{SIMONE}

The averaged path SIMONE-Junior (Järvinen et al., 2016b) was installed in the chamber to provide bulk depolarisation measurements. This instrument technique is in effect comparable to a lidar and is used to detect phase transitions in aerosol, cloud particle ensembles and to investigate the bulk microphysical properties of clouds. The instrument projects a $552 \mathrm{~nm}$ polarised (e.g. perpendicular, parallel and circular) light beam and detects forward- and backward-scattered light from a cloud volume of $30 \mathrm{~cm}^{3}$. Unlike a lidar measurement, parallel and perpendicular components of the backscattered light are measured around the detection angle of $176^{\circ}$, at a very confined angular range with an acceptance angle less than $0.8 \mathrm{mrad}$. The linear depolarisation ratio is expected to be zero for spherical particles and non-zero when particle shapes deviate from spherical. Forward scattering intensity is measured at $4^{\circ}$. The operation of the SIMONE in the CLOUD chamber is described in detail by Järvinen et al. (2016a). The basic instrument concept and data interpretation in case of chamber ice clouds are detailed in Schnaiter et al. (2012).

\subsubsection{Airborne probes}

\section{CASPOL}

The CASPOL installed in the chamber was part of the Cloud, Aerosol, and Precipitation Spectrometer (CAPS, Droplet Measurement Technologies), an instrument commonly used on aircraft for cloud microphysical measurements (e.g. Baumgardner et al., 2001; Johnson et al., 2012; Jones et al., 2012; Luebke et al., 2016; Voigt et al., 2017). The CASPOL relies on incident laser scattering by single particles. The version of CASPOL employed here has a linearly polarised laser to provide a collimated incident beam of light at a wavelength of $680 \mathrm{~nm}$ and a sample area of $\sim 0.225 \mathrm{~mm}^{2}$. The 
collecting optics guide the light scattered in the 4 to $12^{\circ}$ subtended cone into a forward-sizing photodetector. This light is measured and then used to infer a particle size from the calculated scattering cross section. As with most in situ cloud particle spectrometers, CASPOL is calibrated with standard spherical latex and glass spheres. Aspherical particles will therefore be mis-sized (Borrmann et al., 2000) to different degrees. For our experiments, we estimate the sizing error should normally be of the order of the instrument's size bin width (Table S2 in the Supplement).

The backscatter detector measures the scattered light cone subtended between angles 168 and $176^{\circ}$. Additionally, this version of CASPOL was limited to measuring the polarised fraction of the backscattered light in the orthogonal plane for the first 292 particles s $^{-1}$ (Droplet Measurement Technologies Manual, 2011). The sampling air speed of the instrument used in the chamber was set to $\sim 4 \mathrm{~m} \mathrm{~s}^{-1}$. Whilst the highest particle arrival rate could be up to $500 \mathrm{~s}^{-1}$ the average rate was generally below $100 \mathrm{~s}^{-1}$ allowing single particle depolarisation ratios to be calculated for all particles in most cases. The single particle polarisation functionality potentially allows discrimination of aspherical particles in the $0.51-50 \mu \mathrm{m}$ range. For spherical particles, typically droplets, the polarisation of the incident light will be preserved and the orthogonal polarisation in the backscatter will generate nearly zero signal. Depending on the asphericity of the particles, there will be increased signal in the backscatter polarised detector. An increase in size with decrease in polarisation in CASPOL at temperatures below the frost point for example would suggest that ice is sublimating and becoming more spherical as has been observed in cirrus clouds (Jensen et al., 2010). The classification of droplets and ice in CASPOL data analysis is primarily based on applying a polarisation threshold, which needs to be determined from controlled laboratory experiments. A clustering technique is used to discriminate and assign unique particle properties (e.g. asphericity) during the laboratory experiment, primarily based on variations in the polarisation state of the scattered light similarly to the methodology described in Nichman et al. (2016).

\section{V-CPI}

Another aircraft-mounted instrument used here was the CPI, which can image and count particles in the size range of $15-2500 \mu \mathrm{m}$, with the images having a nominal resolution of $2.3 \mu \mathrm{m}$. The version of the $3 \mathrm{~V}$-CPI (SPEC Inc.) used here was an upgraded version of the original CPI described by Lawson et al. (2001) with a particle image acquisition rate of 20 frames per second (fps). The $3 \mathrm{~V}$-CPI version used here was able to generate $400 \mathrm{fps}$. The CPI probe was integrated with a 2D-S optical array probe (Lawson et al., 2006c), which was used as the particle triggering system for the newer CPI imaging system. The particle detection system consists of two intersecting elliptical cross section continuous laser beams $(30 \mathrm{~mW}, 788 \mathrm{~nm})$. For detection, a particle must scatter light from both beams. This in turn triggers the imaging laser (pulsed $80 \mathrm{~W}, 850 \mathrm{~nm}$ ), which fires onto a CCD camera. CPI obtained information covers particle size (including area and volume) and ice habit classification (Lawson et al., 2006b; Um and McFarquhar, 2009; Lindqvist et al., 2012; O'Shea et al., 2016). Complementary size distributions and concentrations data are obtained by the 2D-S. The $3 \mathrm{~V}-\mathrm{CPI}$ is especially suitable for use in ice and mixed-phase clouds (Gayet et al., 2012; Stith et al., 2014). Each of the $2.3 \mu \mathrm{m}$ resolved surface images captured by the CPI can be fitted to a circle function to determine the roundness of the particle (Korolev and Isaac, 2003b). Temporal changes of roundness can be used to calculate the mean non-round (aspherical) concentration fraction. However, the roundness parameter for smallest detected particles of $10 \mu \mathrm{m}$ optical diameter have the largest uncertainty as will be discussed in Sect. 3.2.

The 3V-CPI was mounted on top of the chamber for vertical sampling of larger cloud particles to reduce sedimentation in the sampling lines. The outlet of the instrument was connected to vacuum line and sample air speed of $\sim 4 \mathrm{~m} \mathrm{~s}^{-1}$ was maintained.

\section{Results and discussion}

\subsection{Experimental description}

\subsubsection{Ice nucleation and regrowth}

The air pressure and mean temperature profiles for a typical expansion procedure in accordance with Schnaiter et al. (2016) are presented in Fig. 1a. The expansion starts first with a slow pressure decrease to create water-supersaturated conditions inside the chamber and to form a cloud of supercooled droplets. The expansion rate is increased towards the end in order to achieve ice-supersaturated conditions in a short time period. The overall cooling rate during this expansion was $-4.9^{\circ} \mathrm{C} \min ^{-1}$. The PPD-2K measured the size distribution during the experiment (Fig. 1b). The cloud period with supercooled droplets lasts only several tens of seconds and followed by a fast formation of ice. The depolarisation signal measured by the SIMONE increases only after an increase in the forward scattering signal indicating the short droplet period was followed by transition to the ice phase (Fig. 1c). The expansion is then stopped at $\sim 1 \mathrm{~min}$ (Fig. 1a). Pruppacher and Klett (2010) have suggested a homogeneous ice nucleation rate of $\sim 30 \times 10^{7} \mathrm{~cm}^{-3} \mathrm{~s}^{-1}$ at $-37^{\circ} \mathrm{C}$ (the lowest temperature measured in the chamber at the end of the expansion, Fig. A2). The active fraction can then be estimated in Eq. (1):

$A=1-e^{-J \cdot V \cdot \mathrm{d} t}$,

where $J$ is the homogeneous ice nucleation rate, $V$ is the volume of the droplet $\left(5.24 \times 10^{-10} \mathrm{~cm}^{3}\right.$ for a $10 \mu \mathrm{m}$ droplet $)$ 
and $\mathrm{d} t$ is the time period of the highest supersaturation $(\sim 20 \mathrm{~s})$. Under these conditions, the active fraction is 0.96 .

After the first step of the expansion, the initial temperature of the air volume is slowly restored by the heat flux from the warmer chamber walls, thus creating subsaturated conditions inside the chamber. This warming leads to the sublimation of ice crystals and the observed changes in their microphysical properties. A re-growth of the sublimating ice crystals is initiated at $\sim 11 \mathrm{~min}$, when the pressure decreases from 111.3 to $101.8 \mathrm{kPa}$. The depolarisation signal increases once again during this step and reaches slightly higher levels (0.34) than in the first step (0.26), together with an increase in signal noise level due to the low number concentration. There is also a small increase in the forward scattering but this is much lower than in the first step of the expansion due to $\sim 5$-fold decrease in the concentration. In the first step, the lowest temperature of $\sim-37^{\circ} \mathrm{C}$ is maintained for several tens of seconds and governs the rate of ice nucleation in the turbulent chamber volume. Hence, we assume that ice crystals only remain after the first step and no liquid cloud activation or ice nucleation occurs during the regrowth period (Fig. 1c).

\subsubsection{Size range overlap}

In this comparison, the overlapping size range of PPD-2K and CASPOL for measurements of small ice particles is $7-$ $50 \mu \mathrm{m}$ (Fig. 1b). However, a caveat here is that only $41 \%$ of the particle-by-particle (PBP) polarisation data measured by CASPOL, at $-30^{\circ} \mathrm{C}$, were from particles larger than $7 \mu \mathrm{m}$. At lower temperatures the particle size distribution (PSD) is shifted towards the grey area in Fig. 2, below the PPD$2 \mathrm{~K}$ size cut-off. The fraction of CASPOL PBP polarisation data points due to particles $>7 \mu \mathrm{m}$ at lower temperatures was even lower: $24 \%\left(-40^{\circ} \mathrm{C}\right)$ and $32 \%\left(-50^{\circ} \mathrm{C}\right)$. Thus, most of the particles in the cloud that produce the polarisation data in the CASPOL and the bulk SIMONE depolarisation data are small, $<7 \mu \mathrm{m}$, while in the PPD-2K data $100 \%$ of the analysed particles are $>7 \mu \mathrm{m}$.

The size-segregated aspherical fractions as measured by the PPD-2K in the overlapping size region for the two instruments are presented in Fig. 3. At $-30^{\circ} \mathrm{C}$, the large ice particles reach $20 \mu \mathrm{m}$ in diameter during the first step of the expansion and grow up to $35 \mu \mathrm{m}$ during the second step, within the detection range of CASPOL. Ice particles formed under different temperature regimes would have a different morphology. At cirrus temperatures below $-40^{\circ} \mathrm{C}$, the ice particles form directly from the vapour phase via deposition nucleation (Fig. 3b, c), a different formation pathway compared to ice formation through the liquid phase at $-30^{\circ} \mathrm{C}$ (Fig. 3a). In the final step of the expansion at $-30^{\circ} \mathrm{C}$, during the sublimation period, the aspherical fraction is extremely low, likely due to sphericity ambiguity as will be discussed in Sect. 3.3. For better statistical characterisation, we subsequently examined this process under longer cloud life times

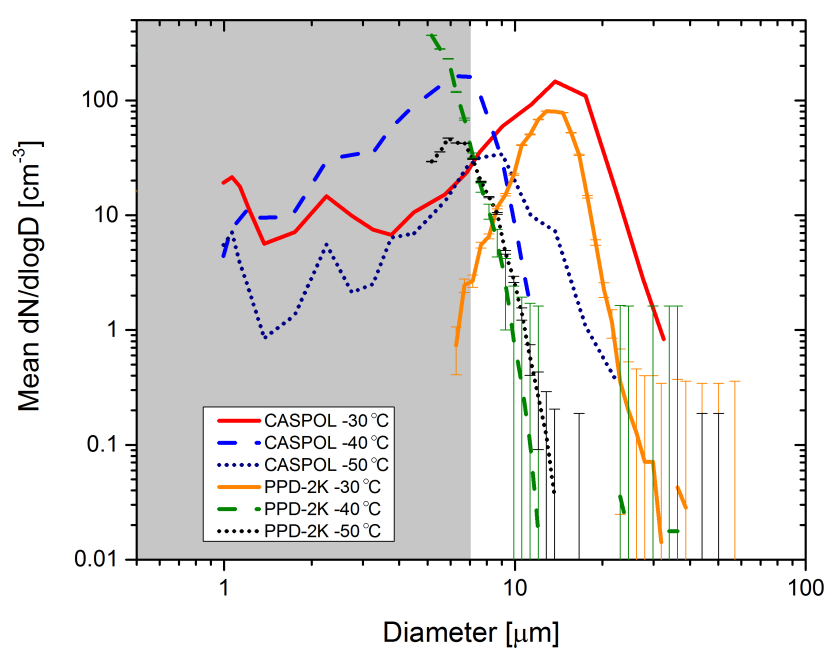

Figure 2. Selected $1 \mathrm{~min}$ averaged particle size distributions $\left(\mathrm{d} N / \mathrm{d} \log D_{\mathrm{p}}\right)$ for experimental runs: $1292.01\left(-30^{\circ} \mathrm{C}\right), 1276.05$ $\left(-40^{\circ} \mathrm{C}\right)$ and $1298.12\left(-50^{\circ} \mathrm{C}\right)$. White area represents the overlap in the size range of PPD-2K and CASPOL. Concentration error bars are shown for the PPD-2K instrument. Grey area represents the size range where most of the particles detected by CASPOL occupy the 292 PBP polarisation bins in a second. This area is mostly below the PPD-2K size cut-off. The aspherical fraction for comparison in Fig. 7 was derived from data within the white area.

(up to $45 \mathrm{~min}$ ) at lower temperatures. However, the measurements of PPD-2K at these temperatures were somewhat incomplete, missing the smaller particle sizes and hence the initial steps of cloud particle formation and growth, especially during the first step of the expansion (Fig. 3b, c). The temperature and $\mathrm{RH}$ profiles of runs, $1276.05\left(-40^{\circ} \mathrm{C}\right)$ and $1298.12\left(-50^{\circ} \mathrm{C}\right)$, are shown in Fig. A1.

\subsubsection{Column fraction}

The ice fraction contains multiple ice habits such as plates and columns in all the regrowth experiments discussed here (Table 1). The largest fraction detected by PPD-2K at cirrus temperatures of -40 and $-50{ }^{\circ} \mathrm{C}$ was typically composed of ice columns as shown in Fig. 4. In the first part of experiment $1292.01\left(-30^{\circ} \mathrm{C}\right)$ the frozen droplets are grown at lower temperature and higher supersaturation than in the second sublimation period of this experiment (Fig. 1a), leading to a formation of more complex particles (Fig. 5). In the regrowth period, the temperature drop and supersaturation conditions are more moderate and we observe the formation of columnar ice particles. The columnar shape, however, is not preserved and the ice particles sublimate, reverting to their underlying spherical core as seen in Fig. 3a. The largest column fractions were measured at the lowest temperature, $-50^{\circ} \mathrm{C}$ (Fig. 4c). In Fig. 5, we collected several typical diffraction patterns from different stages of each of the expansions, marked by vertical dashed lines in Figs. 3 and 4 . The contrast in all the patterns was altered to the same 

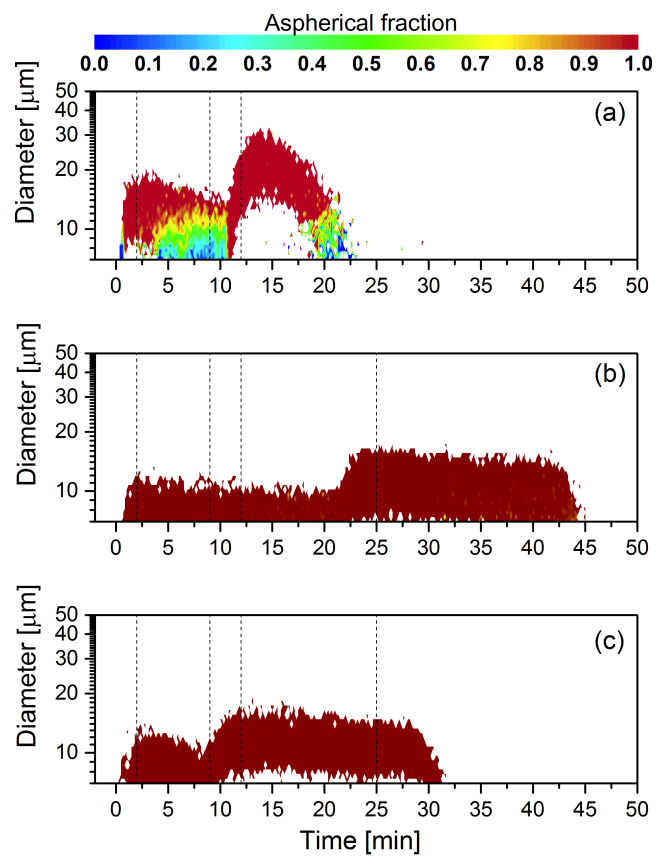

Figure 3. Size-segregated aspherical fraction measured by the PPD2K (see Sect. 2.3.1). (a) Run no. $1292.01\left(-30^{\circ} \mathrm{C}\right)$; (b) run no. $1276.05\left(-40^{\circ} \mathrm{C}\right)$; (c) run no. $1298.12\left(-50^{\circ} \mathrm{C}\right)$. Vertical dashed lines indicate the time of patterns in Fig. 5.

extent to emphasise the presence of speckles in this images. Schnaiter et al. (2016) have linked such speckles to submicron surface features and roughness, i.e. complexity. A particle's surface complexity or non-uniformity will manifest itself as a contributing speckled pattern within the expected idealised diffraction pattern (Järvinen et al., 2016c). Patterns with 2- or 4-fold symmetry are normally identified as columnar habits, whilst patterns with 6-fold symmetry are associated with plate habits. Concentric ring patterns are associated with droplets or quasi-spherical ice. For example, in run 1292.01 we observed the transformation of complex ice to spherical ice to columnar ice (Fig. 5).

The resolution of instrumentation employed in atmospheric measurements, commonly, is not sensitive enough to image the surface microstructural features of the ice crystals. The resolution of the widely used CPI probe is around $2 \mu \mathrm{m}$, i.e. in the same range as the smallest droplets that are frozen into ice crystals and significantly larger than the size of the ice crystals' surface anomalies. Although these anomalies, like roughness and stepped hollowness of the crystal, do not significantly contribute to the mass distribution, they can significantly alter the light scattering properties of the ice crystals, as discussed in Sect. 1.

\subsection{V-CPI image analysis of ice particles}

Substantial concentrations of particles were observed to grow above $20 \mu \mathrm{m}$ in diameter (Fig. 1b), thus allowing their detec-
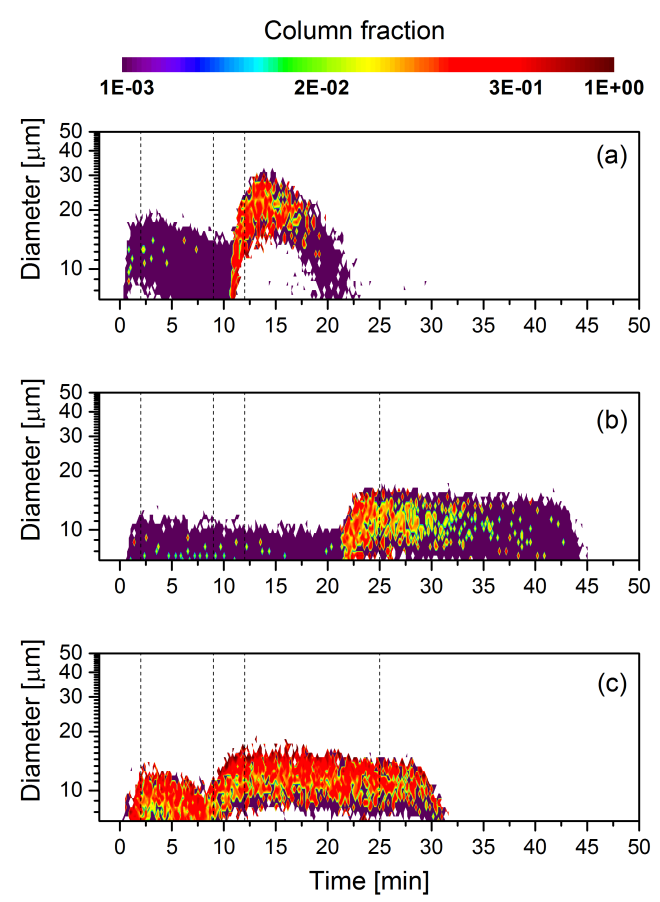

Figure 4. Size-segregated fraction of columns (on log scale), measured by the PPD-2K for (a) run no. $1292.01\left(-30^{\circ} \mathrm{C}\right)$, (b) run no. $1276.05\left(-40^{\circ} \mathrm{C}\right)$ and (c) run no. $1298.12\left(-50^{\circ} \mathrm{C}\right)$. Vertical dashed lines indicate the time of patterns in Fig. 5.

tion with the 3V-CPI. Quasi-spherical, or quasi-spheroidal, small particles were identified from the CPI images (Fig. 6). The CPI imager is triggered by the 2D-S component for particles larger or equal to $10 \mu \mathrm{m}$ as described in Sect. 2.3.3. Image analysis can then provide the roundness of the particles. Due to the larger error in estimating particle roundness at very small sizes, Korolev and Isaac (2003b) have considered the roundness only of those particles with diameter $\geq 20 \mu \mathrm{m}$. Different approaches are used in assessing such thresholds; e.g. Connolly et al. (2007) have included the roundness of smaller particles, $\geq 10 \mu \mathrm{m}$ in diameter, in their analysis using size and shape corrections based on tests with ice analogues to the instrument's depth of field. Emersic et al. (2015) chose a roundness threshold of 0.9 for phase discrimination of particles larger than $35 \mu \mathrm{m}$. The exact definition and calculations of roundness are described in detail in the papers above. In this analysis we consider particles in the range $20-50 \mu \mathrm{m}$ for broader coverage of the CASPOL and PPD-2K overlapping size ranges while constraining the uncertainty in the roundness parameter. Here, the threshold for phase discrimination by roundness was set to 0.9 .

Analysis of a large dataset of CPI images by Korolev et al. (2003) showed that in glaciated clouds a large fraction of particles with diameter $<60 \mu \mathrm{m}$ do indeed have a quasispherical compact shape. Korolev and Isaac (2003b) noted that the question of spherical ambiguity remains due to optical limitations of the instruments. Despite the limitations of 

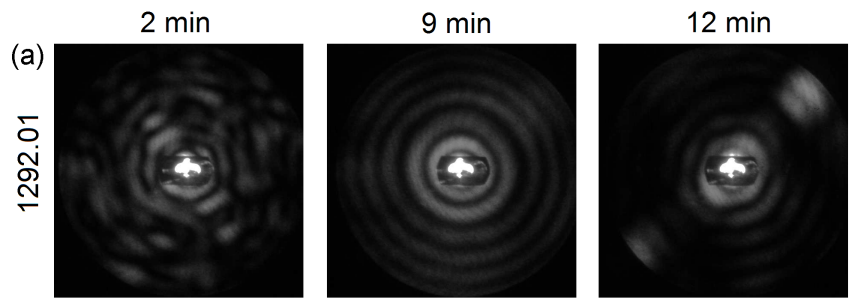

$25 \mathrm{~min}$
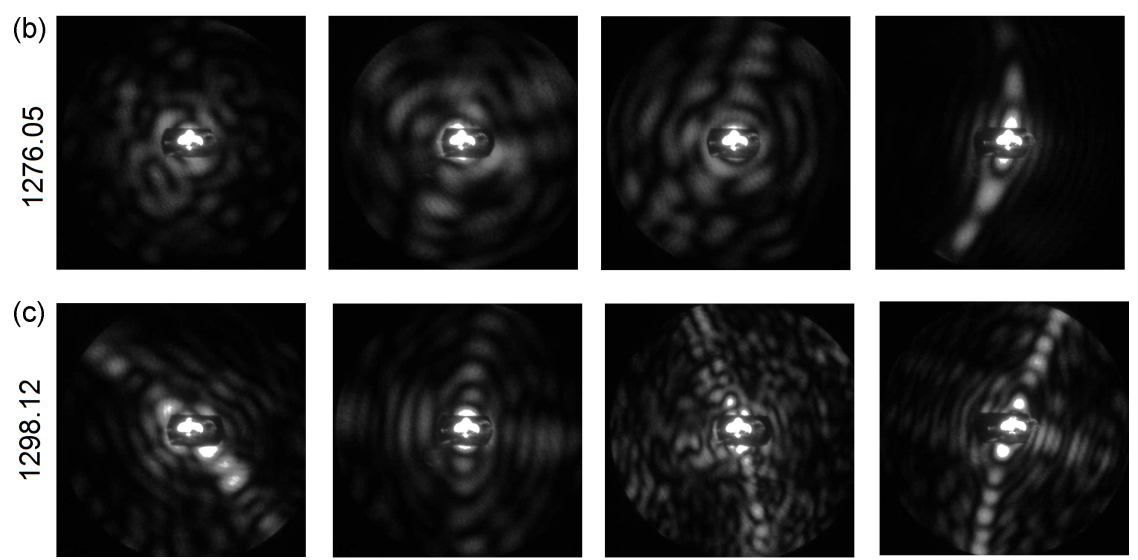

Figure 5. PPD-2K scattering patterns at different stages of the expansion for run no. $1292.01\left(-30^{\circ} \mathrm{C}\right)$ panel row (a), run no. 1276.05 $\left(-40^{\circ} \mathrm{C}\right)$ panel row $(\mathbf{b})$ and run no. $1298.12\left(-50^{\circ} \mathrm{C}\right)$ panel row $(\mathbf{c})$. The time frames are indicated by dashed lines in Figs. 3 and 4. Spheroidal, columnar and other habits with and without submicron features were observed.

size range and resolution, Fig. 7a shows an increase in the non-round image fraction during the growth periods of the ice particles in our chamber experiments.

\subsection{Aspherical fractions measured by PPD-2K, CASPOL and 3V-CPI}

In airborne in situ cloud measurements, ice fractions are commonly derived from the optical asphericity of the particles (Sect. 1). Here we compare PPD-2K and CASPOL single particle measurements to examine their ability to distinguish between droplets and ice particles in different ice nucleation modes. Supercooled droplets may exist until evaporation completes. In experiment no. $1292.01\left(-30^{\circ} \mathrm{C}\right)$, we calculate the evaporation time of $10 \mu \mathrm{m}$ droplet at water saturated environment, assuming instantaneous warmup of gas and droplets, instantaneous drop of RH according to the saturation ratio at the warmer temperature and constant temperature and RH during evaporation. The upper threshold for complete diffusional evaporation in this case is of the order of $20 \mathrm{~s}$ (Eq. 13.18 in Hinds, 1982). We assume that a fraction of the droplets freeze within a short time frame, after their formation, while the rest evaporate or lost to the walls, concluding the duration of the pure liquid cloud in the order of tens of seconds (Fig. 7a). Several tens of seconds after freezing we measure a high ice (aspherical) fraction $(\sim 100 \%)$, as expected. The freezing onset is detected by the increase in the depolarisation signal from the SIMONE and proceeds with an increase in 3V-CPI smoothed non-round fraction (Sect. 3.2) annotated by pink markers, both indicating the presence of non-spherical particles. In the sublimation period, at $4 \mathrm{~min}$, we see the reversed transition in the aspherical fraction; we start to detect more spherical particles that are classified as liquid droplets according to the thresholds used to classify ice (Sect. 2.3; Nichman et al., 2016). The depolarisation finally decreases (Fig. 7a), and particles are no longer detected by the $3 \mathrm{~V}$-CPI due to their decrease in size below the threshold. The size-segregated aspherical fraction measured by the PPD-2K for this experiment is shown in Fig. 3a.

During the sublimation period the aspherical fraction decreases, implying increasing sphericity of the particles (Fig. 7a). However, once full glaciation was observed, the liquid phase cannot subsequently exist at the ambient chamber temperature, below $-30^{\circ} \mathrm{C}$. Therefore, the nearly spherical particles observed (4-10 min and from 19 min onwards) are spherical ice and not liquid water droplets. The formation of optically spherical ice particles in chamber experiments was first shown by Järvinen et al. (2016c). In atmospheric measurements, such an aspherical fraction would normally be converted into an ice fraction. In this cloud simulation, at the end of the sublimation period, both PPD-2K and CASPOL misinterpret the total ice fraction as sphericalliquid by $60 \%$.

In experiments $1276.05\left(-40^{\circ} \mathrm{C}\right)$ and $1298.12\left(-50^{\circ} \mathrm{C}\right)$ (Fig. 7b, c), we observe a short increase in aspherical fraction measured by the $3 \mathrm{~V}$-CPI at $-40^{\circ} \mathrm{C}$ and insufficient data 


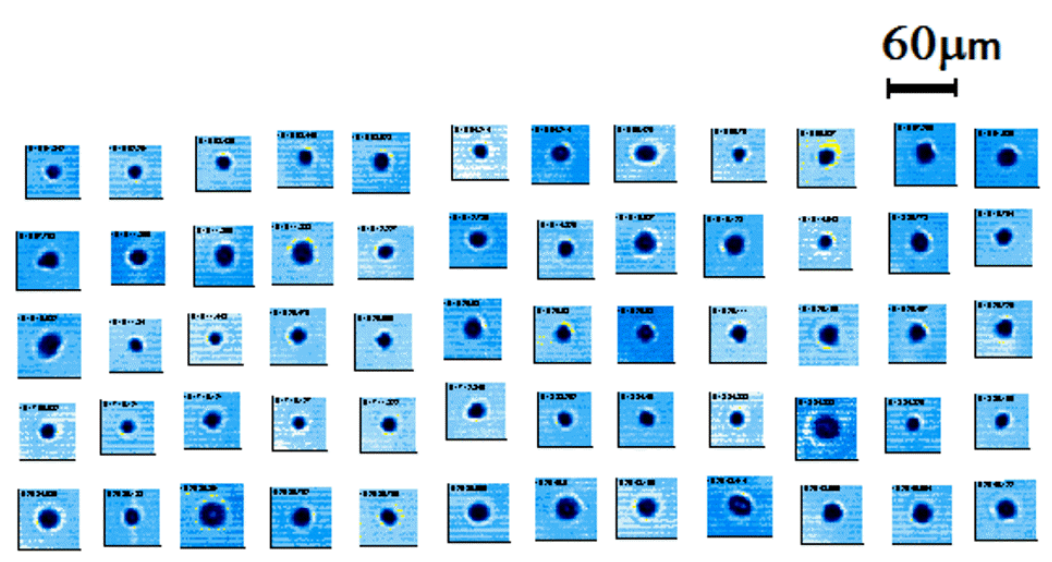

Figure 6. Experimental run no. 1292.01. 3V-CPI images of frozen droplets immediately after ice phase transition. The shape analysis of these particles is presented in Fig. 7.

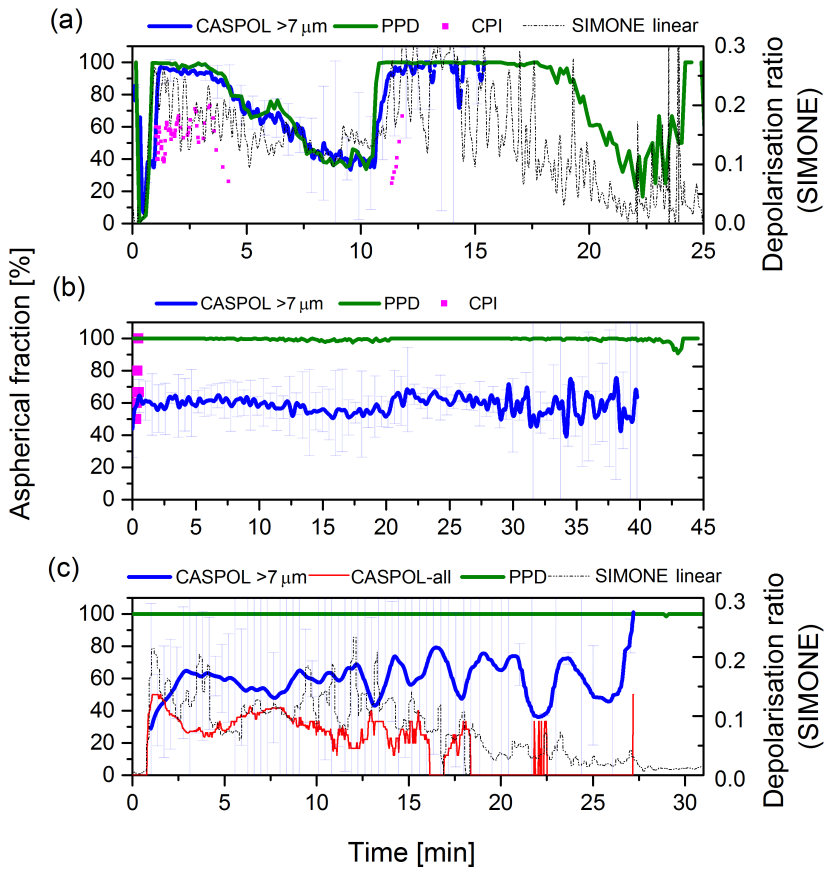

Figure 7. PPD-2K (green line) and CASPOL (blue line with standard deviation error bars) aspherical fraction of a subgroup of particles with diameters $>7 \mu \mathrm{m}$. The intercomparison complemented by SIMONE linear depolarisation ratio (dashed line), CASPOL aspherical fraction for all diameters (red line) and 3V-CPI non-round (aspherical) fraction (magenta rectangles). (a) Run no. 1292.01 $\left(-30^{\circ} \mathrm{C}\right)$; (b) run no. $1276.05\left(-40^{\circ} \mathrm{C}\right)$; (c) run no. 1298.12 $\left(-50^{\circ} \mathrm{C}\right)$.

in this size range at $-50^{\circ} \mathrm{C}$. Up to $40 \%$ lower aspherical fraction is measured by the CASPOL at these temperatures. Polarisation data analysis therefore suggests that ice particles smaller than $7 \mu \mathrm{m}$ are more spherical at lower temperatures (Fig. 7c red line) and they are more abundant (Sect. 3.1.2). Furthermore, the aspherical fraction for all particles detected in the PBP mode in CASPOL at $-50^{\circ} \mathrm{C}$ follows the SIMONE depolarisation time series while the aspherical fraction of CASPOL $>7 \mu \mathrm{m}$ subgroup is higher and increases towards the end of the expansion (Fig. 7c). The size dependence of these two polarisation detection techniques is demonstrated in Sect. 3.4. However, analysis of the scattering patterns detected by the PPD-2K resulted in a $100 \%$ aspherical fraction in both experiments with vapour-formed ice crystals (Fig. 5). Additional studies are required to confirm these trends.

Similar discrepancies in aspherical fraction measurements by PPD-2K and CASPOL have already been shown in Järvinen et al. (2016c) for ice particles formed via homogeneous nucleation and via deposition nucleation on mineral dust at $-30^{\circ} \mathrm{C}$. The asphericity of the particles significantly differs for ice formed through the liquid phase and ice formed through the vapour phase. These discrepancies (Fig. 7b, c) at lower temperatures can be partially explained by the decrease in the number of particles measured in every second and therefore the increased standard deviation in the aspherical fraction calculation, i.e. $19 \%$ for particles $>7 \mu \mathrm{m}$ at $-40{ }^{\circ} \mathrm{C}$ and $37 \%$ for particles $>7 \mu \mathrm{m}$ at $-50^{\circ} \mathrm{C}$. However, the smaller size of particles at -40 and $-50{ }^{\circ} \mathrm{C}$ is the main cause of reduced sensitivity of the polarisation measurements with respect to aspherical features.

\subsection{Single particle polarisation and ensemble depolarisation ratios}

This analysis aimed at improving our interpretation of the small ice particle polarisability and the comparison of different instruments and their approaches to discriminate small liquid and ice phase cloud particles by properties of their scattered light. One such property is the linear depolarisation ratio for parallel incident laser polarisation $\delta_{\|}$, which is defined as the perpendicularly polarised to parallel polarised ratio of the backscattered light intensity $\left(I_{\perp} / I_{||}\right)$. 


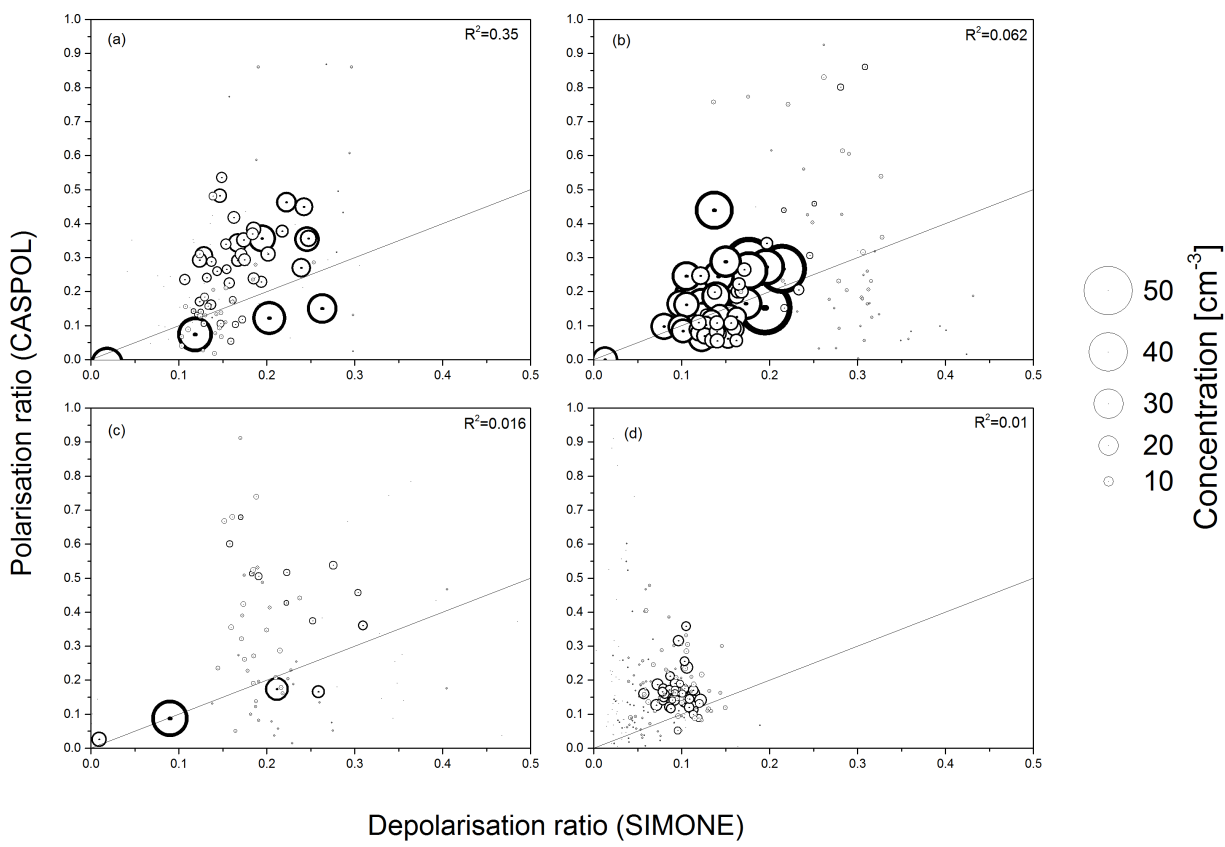

Figure 8. CASPOL polarisation and SIMONE depolarisation comparison for runs (a) no. 1292.01, (b) no. 1291.07, (c) no. 1291.12 and (d) no. 1298.20. For details, see Table 1. Marker size denotes number concentration; maximum concentration observed was $56 \mathrm{~cm}^{-3}$. Black reference line is the $1: 1$ ratio. Higher $R^{2}$ values are observed for clouds with higher concentrations of smaller particles.

This ratio is frequently used in remote sensing (e.g. Burton et al., 2012; Petzold et al., 2010). The linear polarisation ratio in CASPOL data analysis is defined as the fraction of the perpendicularly polarised backscattered light from the total backscattered intensity (Dpol / Back) as previously reported (Glen and Brooks, 2013) and is used for ice fraction derivation (Nichman et al., 2016). The particle detection method and the measured polarisation components are not the only dissimilarities in these instruments, however, as they also operate at different wavelengths, have slightly different collection angles and have a difference of more than two orders of magnitude in their sample volumes, as described above.

The depolarisation ratio measured by the SIMONE and the polarisation ratio measured by the CASPOL were plotted against each other with $1 \mathrm{~s}$ temporal resolution for run no. 1292.01 (where high concentrations of particles dominated), no. 1291.12 (where low concentrations and large particle diameters dominated), no. 1291.07 (where high concentrations and small particle diameters dominated) and no. 1298.2 (where low concentrations and small particle diameters dominated) (Table 1). The results are shown in Figs. 8 and 9. The relative dimensions of the marker reflect the number concentration, with the highest at $56 \mathrm{~cm}^{-3}$. The CASPOL polarisation ratios presented here are based on $1 \mathrm{~s}$ averages for all particles larger than $3 \mu \mathrm{m}$. Small aerosol particles $(<3 \mu \mathrm{m})$ were detected during background measurements, after $\mathrm{CCN}$ injection and before the expansion. These small particles, i.e. non-activated aerosols, were excluded from further analysis.
In correlation analysis, the lowest $R^{2}$ values were found at low concentration experiments, where the detected polarisation was higher than the depolarisation. This is partially due to large deviations that occurred at low concentration within the larger sample volume of the SIMONE instrument. These deviations are highly affected by occasional poor mixing conditions in the chamber after the expansion is completed. We have observed a higher $R^{2}$ value in cases with high concentration of cloud particles $\left(R^{2} \sim 0.35\right)$ (Figs. 8a, $\mathrm{b}, 9 \mathrm{a}, \mathrm{b})$ and significantly lower value $\left(R^{2} \sim 0.01\right)$ in cases with low concentrations and smaller sizes of cloud particles as might be expected based on the relative sample volumes. Analysis of run 1292.01 showed that the column fraction had no effect on the $R^{2}$ value in this run (Table $\mathrm{S} 3$ ).

\subsection{Implications for atmospheric measurements}

The misclassification of quasi-spherical ice as liquid droplets can pose a problem with in situ atmospheric measurements and especially in mixed-phase clouds, particularly when attempting to determine ice phase transition and longevity. Ice fraction calculations using current measurement techniques can be significantly affected by the potential misinterpretations highlighted by the results shown in these cloud chamber experiments. In the atmosphere, there are additional possible crystal rounding mechanisms, e.g. equilibrium thermal roughening near $0^{\circ} \mathrm{C}$, a surface coating of solutions, kinetic roughening at high supersaturations and latent heat-induced melting of the surface during growth at high temperatures 


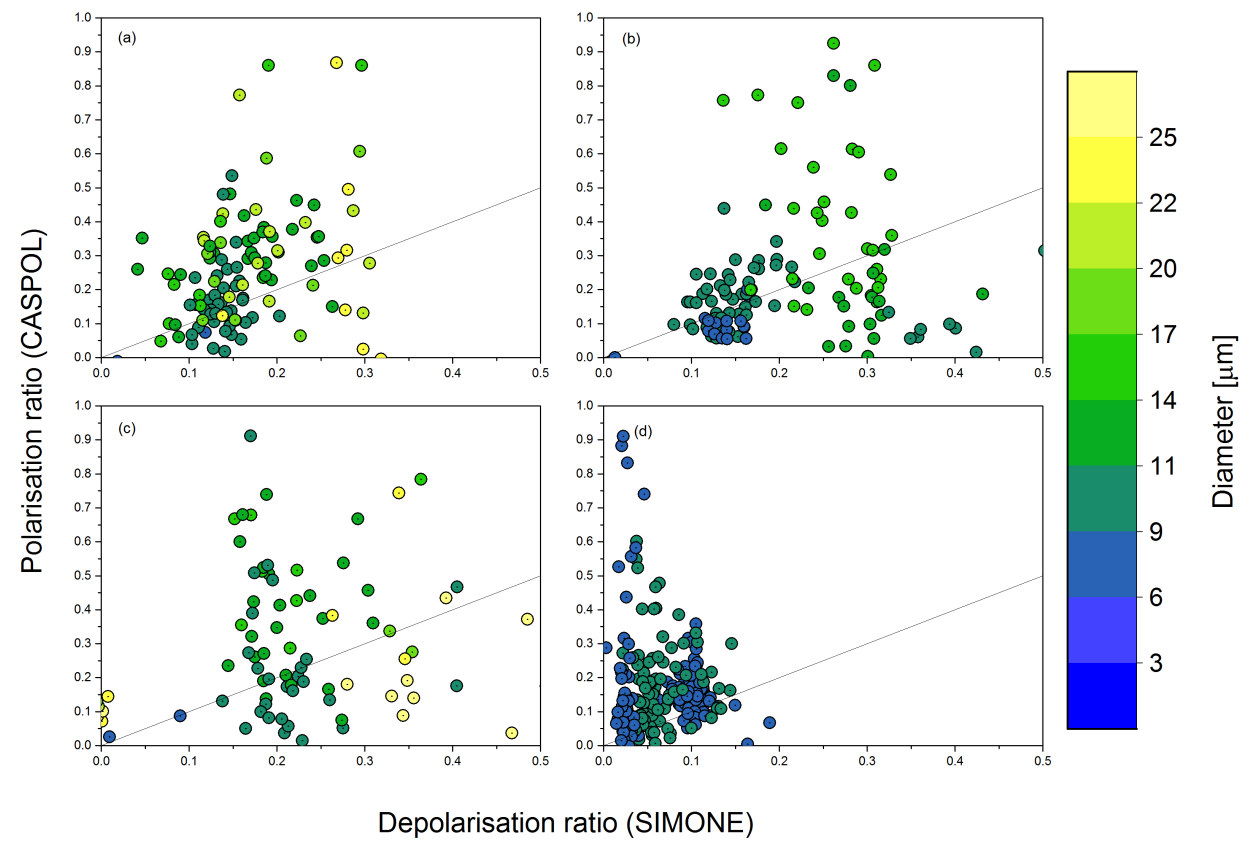

Figure 9. CASPOL polarisation and SIMONE depolarisation comparison for runs (a) no. 1292.01, (b) no. 1291.07, (c) no. 1291.12 and (d) no. 1298.20. For details, see Table 1. Mean particle diameter is colour coded. Black reference line is the $1: 1$ ratio.

and supersaturation. In addition, frozen droplets retain their rounded appearance until sufficient growth occurs. Therefore, it is not possible to infer subsaturated conditions in the atmosphere merely by sampling rounded crystals (Nelson, 1998) and the measured ice fraction may be prone to significant underestimation. In any case of small quasi-spherical particle detection at sub-zero temperatures in the atmosphere, we recommend to use multiple instruments for intercomparative analysis.

Aspherical fraction derived from CASPOL data can be compared to other instruments with greater confidence when the PSD is fully covered by the overlapped size and concentration range of the instruments with sufficient number of particles for aspherical fraction derivation with low standard deviation. However, artefacts such as shattering, compression and coincidence (Lance et al., 2012; Wendisch and Brenguier, 2013) that may occur in airborne measurement may also lead to a mis-estimation of the ice fraction. In this study, due to low concentrations, particle coincidence in the CASPOL sample volume is minimal. In cases where small particle arrival rates and concentrations do not exceed the values reported here, the findings of this study may be applicable.

The comparison of remote sensing and PBP measurements is not a straightforward process (i.e. bulk vs. single particle and single complexity vs. mixed-complexity ensembles of particles). Many single particle and ensemble measurements laboratory techniques in particular have proven difficult to adopt when translated to real atmospheric environments. These techniques often provide complementary data rather than comparable data (Lynch, 2001) and research in this area continues (e.g. Ray and Anderson, 2015).

Recent efforts to classify clouds (e.g. Krämer et al., 2016; Luebke et al., 2016) by their microphysical properties do not account for particle morphology; the morphology of small ice formed in situ in cirrus clouds or cirrus of liquid origin in the first steps of homogeneous freezing may affect the scattering properties and hence the solar radiation budget. According to the findings in this paper, submicron features might be present, but undetectable using some instruments at lower temperatures or for small particle sizes $(<7 \mu \mathrm{m})$. These phenomena may increase scattering and thus intensify cooling. The lack of these features in liquid origin clouds in warmer subzero temperature may allow more efficient warming. However, this needs to be further investigated.

\section{Conclusions}

We have presented an instrumental set-up for combined single cloud particle and ensemble measurements for assessment of the relative optical ice and liquid responses in each case. The results were used to examine the asphericity evolution during adiabatic expansion, sublimation and regrowth as well as to assess the potential impact on phase discrimination by the different measurement techniques. We report observations of supercooled and frozen droplets and small ice habits including spheroids in a series of CLOUD chamber experiments at $-30,-40$ and $-50^{\circ} \mathrm{C}$. 
Poor agreement was found between PPD-2K and CASPOL asphericity for small ice crystals in the experiments at -40 and $-50^{\circ} \mathrm{C}$. However, in the frozen droplet experiments these instruments were in good agreement (Fig. 7a). We have shown that the small quasi-spherical ice particles produced in the sublimation process exhibit a similar optical behaviour to that of water droplets as measured by the PPD$2 \mathrm{~K}$ using variance analysis, and in the CASPOL, using polarisation analysis for high PSD overlap at $-30{ }^{\circ} \mathrm{C}$. The analysis of the PPD-2K scattering patterns for water droplets and sublimating ice shows the similarity of the spherical states and the difficulty in applying phase discrimination. Therefore, in liquid-origin cirrus observations of small spheroids $(<35 \mu \mathrm{m})$ in subsaturated conditions, none of the instruments can confidently distinguish ice from water. These results indicate that small quasi-spherical ice misclassification might similarly concern numerous optical instruments, impactors and other probes not examined here. Järvinen et al. (2016c) proposed a hypothesis of surface frost layer development on the frozen droplets during the freezing and initial growth periods. However, the contribution to, for example, the net polarisation signature by this very thin layer is too weak to be detected by the CASPOL and SIMONE if the particles retain their sphericity. At this stage, the phase of small spherical particles cannot be unambiguously defined with any of the instruments examined here. Nonetheless, there is evidence that scattering patterns may differ for quasispherical ice and water due to small deviations from sphericity as indicated by changes in a complexity analysis metric (e.g. Schnaiter et al., 2016; Järvinen et al., 2016c; Voigt et al., 2017) and appearance of speckled patterns which could be used to solve the phase ambiguity. An increase in resolution in future versions of these optical instruments might better amplify such difference and allow easier discrimination as well as revealing additional subtle morphological features and associated processes. However, in atmospheric measurements, small particle detection may be contaminated by shattering; therefore coincidence should be addressed before any comparison can be made.
We conclude that in these simulated atmospheric conditions the polarisation and depolarisation signatures from frozen droplets have higher $R^{2}$ values at higher concentrations of small particles and can be comparable above certain concentration and size thresholds. These findings and the derived instrumental differences may be used in the interpretation of atmospheric measurements of frozen droplets from field measurements using combined remote and in situ measurement approaches as well as a pathway for further research and development for improvements to these instruments.

Data availability. Datasets from all the collaboration instruments are stored on Lisbon servers, ordered by campaign serial numbers, and can be accessed from the collaboration website: http:// cloud.sim.ul.pt/. Access requests should be directed to the CLOUD project administrator. Backups of the data measured by University of Manchester are stored on the departmental server of the School of Earth and Environmental Sciences in Database3. 


\section{Appendix A}

Figure A1 presents the temperature profile of the complementary adiabatic expansions at -40 and $-50^{\circ} \mathrm{C}$. The resulting RH conditions are annotated on the right $y$ axis.

Figure A2 presents the residuals from the mean temperature in the vertical direction, relative to the centre of the chamber during the first expansion of run no. 1292.01. Most of the non-uniformities in temperature across the chamber occur at the very end of the expansion.
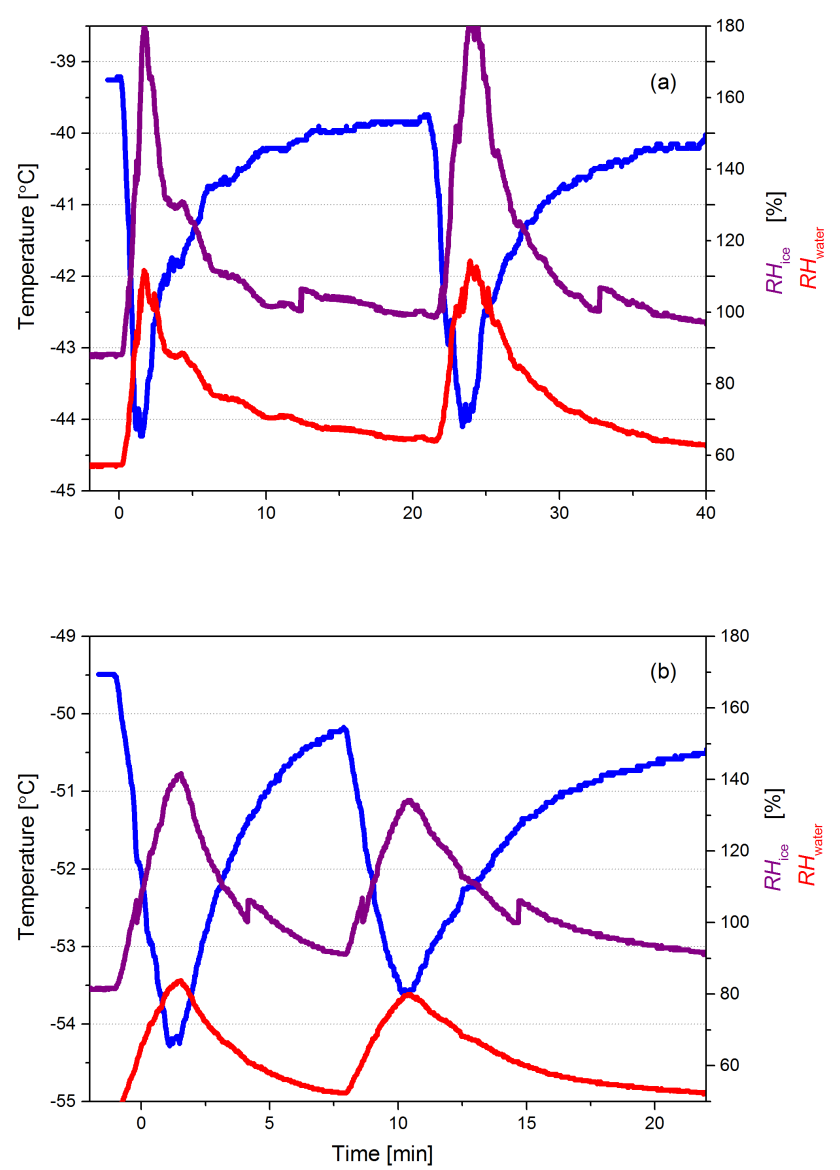

Figure A1. Temperature $\left(T^{\circ} \mathrm{C}\right)$ profiles and $\mathrm{RH}$, versus time for (a) run no. $1276.05\left(-40^{\circ} \mathrm{C}\right)$ and (b) run no. $1298.12\left(-50^{\circ} \mathrm{C}\right)$.

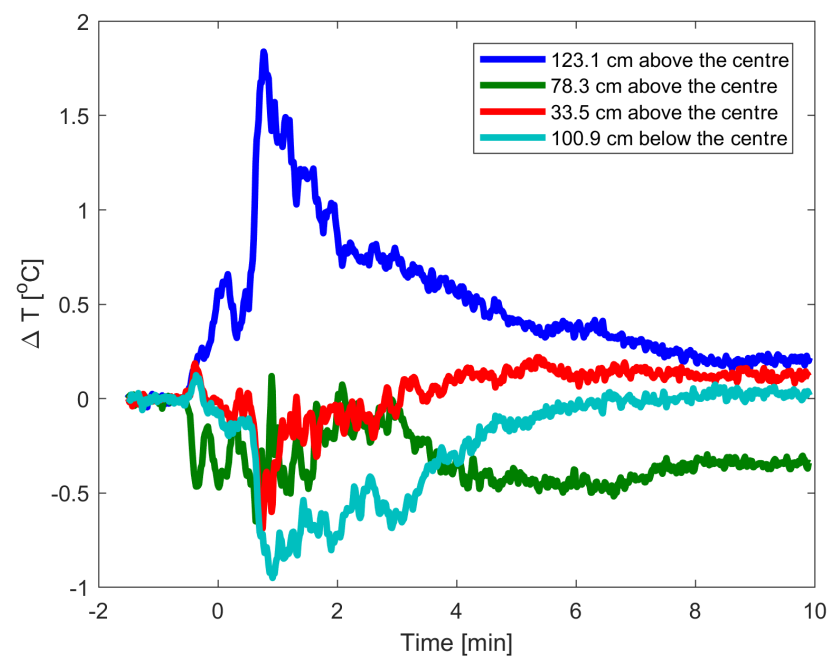

Figure A2. CLOUD chamber vertical temperature residuals relative to the centre of the chamber. First expansion of run no. 1292.01. 


\section{The Supplement related to this article is available online at https://doi.org/10.5194/amt-10-3231-2017-supplement.}

Competing interests. The authors declare that they have no conflict of interest.

Acknowledgements. We would like to thank CERN for supporting CLOUD with important technical and financial resources. We express great appreciation for the CLOUD collaboration. This research has received funding from the EC Seventh Framework Programme (Marie Curie Initial Training Network "CLOUDTRAIN" no. 316662). The SIMONE measurements were funded by the CERN CLOUD project. The PPD-2K instrument was fully funded by the Deutsche Forschungsgemeinschaft within project SCHN 1140/2-1. The CAPS and 3V-CPI instruments used in this work, and support staff were supplied by the UK National Centre for Atmospheric Science (NCAS).

Edited by: Pierre Herckes

Reviewed by: four anonymous referees

\section{References}

Abdelmonem, A., Järvinen, E., Duft, D., Hirst, E., Vogt, S., Leisner, T., and Schnaiter, M.: PHIPS-HALO: the airborne Particle Habit Imaging and Polar Scattering probe - Part 1: Design and operation, Atmos. Meas. Tech., 9, 3131-3144, https://doi.org/10.5194/amt-9-3131-2016, 2016.

Ackerman, A. S., Fridlind, A. M., Grandin, A., Dezitter, F., Weber, M., Strapp, J. W., and Korolev, A. V.: High ice water content at low radar reflectivity near deep convection - Part 2: Evaluation of microphysical pathways in updraft parcel simulations, Atmos. Chem. Phys., 15, 11729-11751, https://doi.org/10.5194/acp-1511729-2015, 2015.

Baumgardner, D., Jonsson, H., Dawson, W., O'Connor, D., and Newton, R.: The cloud, aerosol and precipitation spectrometer: a new instrument for cloud investigations, Atmos. Res., 59, 251264, https://doi.org/10.1016/S0169-8095(01)00119-3, 2001.

Baumgardner, D., Newton, R., Krämer, M., Meyer, J., Beyer, A., Wendisch, M., and Vochezer, P.: The Cloud Particle Spectrometer with Polarization Detection (CPSPD): A next generation open-path cloud probe for distinguishing liquid cloud droplets from ice crystals, Atmos. Res., 142, 2-14, https://doi.org/10.1016/j.atmosres.2013.12.010, 2014.

Baumgardner, D., Abel, S. J., Axisa, D., Cotton, R., Crosier, J., Field, P., Gurganus, C., Heymsfield, A., Korolev, A., Krämer, M., Lawson, P., McFarquhar, G., Ulanowski, Z., and Um, J.: Cloud Ice Properties: In Situ Measurement Challenges, Meteorological Monographs, 58, 9.1-9.23, https://doi.org/10.1175/AMSMONOGRAPHS-D-16-0011.1, 2017.

Borrmann, S., Luo, B., and Mishchenko, M.: Application of the T-matrix method to the measurement of aspherical (ellipsoidal) particles with forward scattering optical particle coun- ters, J. Aerosol Sci., 31, 789-799, https://doi.org/10.1016/S00218502(99)00563-7, 2000.

Buck: Buck Research CR-1A User's Manual, Appendix 1, available at: http://www.hygrometers.com/wp-content/uploads/ CR-1A-users-manual-2009-12.pdf (1 May 2016), 1996.

Burton, S. P., Ferrare, R. A., Hostetler, C. A., Hair, J. W., Rogers, R. R., Obland, M. D., Butler, C. F., Cook, A. L., Harper, D. B., and Froyd, K. D.: Aerosol classification using airborne High Spectral Resolution Lidar measurements - methodology and examples, Atmos. Meas. Tech., 5, 73-98, https://doi.org/10.5194/amt-5-732012, 2012.

Byers, H. R. and Braham, R. R.: Thunderstorm structure and circulation, J. Meteor., 5, 71-86, https://doi.org/10.1175/15200469(1948)005<0071:TSAC>2.0.CO;2, 1948.

Cober, S. G., Isaac, G. A., Korolev, A. V., and Strapp, J. W.: Assessing Cloud-Phase Conditions, J. Appl. Meteorol., 40, 1967-1983, https://doi.org/10.1175/15200450(2001)040<1967:ACPC>2.0.CO;2, 2001.

Connolly, P. J., Flynn, M. J., Ulanowski, Z., Choularton, T. W., Gallagher, M. W., and Bower, K. N.: Calibration of the Cloud Particle Imager Probes Using Calibration Beads and Ice Crystal Analogs: The Depth of Field, J. Atmos. Ocean. Technol., 24, 1860-1879, https://doi.org/10.1175/JTECH2096.1, 2007.

Cotton, R., Osborne, S., Ulanowski, Z., Hirst, E., Kaye, P. H., and Greenaway, R. S.: The Ability of the Small Ice Detector (SID-2) to Characterize Cloud Particle and Aerosol Morphologies Obtained during Flights of the FAAM BAe146 Research Aircraft, J. Atmos. Ocean. Tech., 27, 290-303, https://doi.org/10.1175/2009JTECHA1282.1, 2010.

Dias, A., Ehrhart, S., Vogel, A., Williamson, C., Almeida, J., Kirkby, J., Mathot, S., Mumford, S., and Onnela, A.: Temperature uniformity in the CERN CLOUD chamber, Atmos. Meas. Tech. Discuss., https://doi.org/10.5194/amt-2017-114, in review, 2017.

Droplet Measurement Technologies Manual: CAPS operator manual, DOC-0066 Revision F, DMT, Boulder, Colorado, USA, 2011.

Duplissy, J., Merikanto, J., Franchin, A., Tsagkogeorgas, G., Kangasluoma, J., Wimmer, D., Vuollekoski, H., Schobesberger, S., Lehtipalo, K., Flagan, R., Brus, D., Donahue, N., Vehkämäki, H., Almeida, J., Amorim, A., Barmet, P., Bianchi, F., Breitenlechner, M., Dunne, E., Guida, R., Henschel, H., Junninen, H., Kirkby, J., Kürten, A., Kupc, A., Määttänen, A., Makhmutov, V., Mathot, S., Nieminen, T., Onnela, A., Praplan, A., Riccobono, F., Rondo, L., Steiner, G., Tome, A., Walther, H., Baltensperger, U., Carslaw, K., Dommen, J., Hansel, A., Petäjä, T., Sipilä,M., Stratmann, F., Vrtala, A., Wagner, P., Worsnop, D., Curtius, J., and Kulmala, M.: Effect of ions on sulfuric acid-water binary particle formation II: Experimental data and comparison with QC-normalized classical nucleation theory, J. Geophys. Res.-Atmos., 121, 1752 1775, https://doi.org/10.1002/2015JD023539, 2016.

Elliott, J. W. and Smith, F. T.: Ice formation on a smooth or rough cold surface due to the impact of a supercooled water droplet, J. Eng. Math., 102, 35-64, https://doi.org/10.1007/s10665-0159784-z, 2015.

Emersic, C., Connolly, P. J., Boult, S., Campana, M., and Li, $\mathrm{Z}$ : Investigating the discrepancy between wet-suspensionand dry-dispersion-derived ice nucleation efficiency of 
mineral particles, Atmos. Chem. Phys., 15, 11311-11326, https://doi.org/10.5194/acp-15-11311-2015, 2015.

Gallagher, M. W., Baumgardner, D., Lloyd, G., Beswick, K., Freer, M., and Durant, A.: Detection and Analysis of High Ice Concentration Events and Supercooled Drizzle from IAGOS Commercial Aircraft, Geophys. Res. Abstr., EGU2016-2924, EGU General Assembly 2016, Vienna, Austria, 2016.

Garrett, T. J., Navarro, B. C., Twohy, C. H., Jensen, E. J., Baumgardner, D. G., Bui, P. T., Gerber, H., Herman, R. L., Heymsfield, A. J., Lawson, P., Minnis, P., Nguyen, L., Poellot, M., Pope, S. K., Valero, F. P. J., and Weinstock, E. M.: Evolution of a Florida Cirrus Anvil, J. Atmos. Sci., 62, 2352-2372, 2005.

Gayet, J.-F., Mioche, G., Shcherbakov, V., Gourbeyre, C., Busen, R., and Minikin, A.: Optical properties of pristine ice crystals in mid-latitude cirrus clouds: a case study during CIRCLE-2 experiment, Atmos. Chem. Phys., 11, 2537-2544, https://doi.org/10.5194/acp-11-2537-2011, 2011.

Gayet, J.-F., Mioche, G., Bugliaro, L., Protat, A., Minikin, A., Wirth, M., Dörnbrack, A., Shcherbakov, V., Mayer, B., Garnier, A., and Gourbeyre, C.: On the observation of unusual high concentration of small chain-like aggregate ice crystals and large ice water contents near the top of a deep convective cloud during the CIRCLE-2 experiment, Atmos. Chem. Phys., 12, 727-744, https://doi.org/10.5194/acp-12-727-2012, 2012.

Glen, A. and Brooks, S. D.: A new method for measuring optical scattering properties of atmospherically relevant dusts using the Cloud and Aerosol Spectrometer with Polarization (CASPOL), Atmos. Chem. Phys., 13, 1345-1356, https://doi.org/10.5194/acp-13-1345-2013, 2013.

Guida, R., Carrie, P., De Menezes, L., Duplissy, J., Fayet, F., Kirkby, J., Mathot, S., Minginette, P., Onnela, A., Rochez, J., Thomas, G., Wasem, A., and Wilhelmsson, M.: An ultra-pure gas system for the CLOUD experiment at CERN, in: 2012 IEEE Nuclear Science Symposium and Medical Imaging Conference (NSS/MIC), 27 October-3 November 2012, Anaheim, CA, 1199-1203, 2012.

Guida, R., Carrie, P., De Menezes, L., Duplissy, J., Fayet, F., Haider, S., Kirkby, J., Mathot, S., Minginette, P., Onnela, A., Rochez, J., Thomas, G., Wasem, A., and Wilhelmsson, M.: Development of the gas system for the CLOUD experiment at CERN, in: Nuclear Science Symposium and Medical Imaging Conference (NSS/MIC), 2013 IEEE, Seoul 27 October-2 November 2013, $1-5,2013$.

Heymsfield, A. J., Miloshevich, L. M., Schmitt, C., Bansemer, A., Twohy, C., Poellot, M. R., Fridlind, A., and Gerber, H.: Homogeneous Ice Nucleation in Subtropical and Tropical Convection and Its Influence on Cirrus Anvil Microphysics, J. Atmos. Sci., 62, 41-64, https://doi.org/10.1175/JAS-3360.1, 2005.

Hinds, W. C.: Aerosol Technology John Wiley and Sons, New York, 424, 1982.

Hirst, E., Kaye, P. H., Greenaway, R. S., Field, P., and Johnson, D. W.: Discrimination of micrometre-sized ice and super-cooled droplets in mixed-phase cloud, Atmos. Environ., 35, 33-47, https://doi.org/10.1016/S1352-2310(00)00377-0, 2001.

Irvine, E. A. and Shine, K. P.: Ice supersaturation and the potential for contrail formation in a changing climate, Earth Syst. Dynam., 6, 555-568, https://doi.org/10.5194/esd-6-555-2015, 2015.

Järvinen, E., Ignatius, K., Nichman, L., Kristensen, T. B., Fuchs, C., Hoyle, C. R., Höppel, N., Corbin, J. C., Craven, J., Duplissy, J., Ehrhart, S., El Haddad, I., Frege, C., Gordon, H., Joki- nen, T., Kallinger, P., Kirkby, J., Kiselev, A., Naumann, K.-H., Petäjä, T., Pinterich, T., Prevot, A. S. H., Saathoff, H., Schiebel, T., Sengupta, K., Simon, M., Slowik, J. G., Tröstl, J., Virtanen, A., Vochezer, P., Vogt, S., Wagner, A. C., Wagner, R., Williamson, C., Winkler, P. M., Yan, C., Baltensperger, U., Donahue, N. M., Flagan, R. C., Gallagher, M., Hansel, A., Kulmala, M., Stratmann, F., Worsnop, D. R., Möhler, O., Leisner, T., and Schnaiter, M.: Observation of viscosity transition in a-pinene secondary organic aerosol, Atmos. Chem. Phys., 16, 4423-4438, https://doi.org/10.5194/acp-16-4423-2016, 2016 a.

Järvinen, E., Kemppinen, O., Nousiainen, T., Kociok, T., Möhler, O., Leisner, T., and Schnaiter, M.: Laboratory investigations of mineral dust near-backscattering depolarization ratios, J. Quant. Spectrosc. Ra., 178, 192-208, https://doi.org/10.1016/j.jqsrt.2016.02.003, 2016b.

Järvinen, E., Schnaiter, M., Mioche, G., Jourdan, O., Shcherbakov, V. N., Costa, A., Afchine, A., Krämer, M., Heidelberg, F., Jurkat, T., Voigt, C., Schlager, H., Nichman, L., Gallagher, M., Hirst, E., Schmitt, C., Bansemer, A., Heymsfield, A., Lawson, P., Tricoli, U., Pfeilsticker, K., Vochezer, P., Möhler, O., and Leisner, T.: Quasi-Spherical Ice in Convective Clouds, J. Atmos. Sci., 73, 3885-3910, https://doi.org/10.1175/JAS-D-15-0365.1, 2016c.

Jeanne, M., Walter, S., and Philip, C.: The Ice Particle Threat to Engines in Flight, in: 44th AIAA Aerospace Sciences Meeting and Exhibit, Aerospace Sciences Meetings, American Institute of Aeronautics and Astronautics, 2006.

Jensen, E. J., Lawson, P., Baker, B., Pilson, B., Mo, Q., Heymsfield, A. J., Bansemer, A., Bui, T. P., McGill, M., Hlavka, D., Heymsfield, G., Platnick, S., Arnold, G. T., and Tanelli, S.: On the importance of small ice crystals in tropical anvil cirrus, Atmos. Chem. Phys., 9, 5519-5537, https://doi.org/10.5194/acp-95519-2009, 2009.

Jensen, E. J., Pfister, L., Bui, T.-P., Lawson, P., and Baumgardner, D.: Ice nucleation and cloud microphysical properties in tropical tropopause layer cirrus, Atmos. Chem. Phys., 10, 1369-1384, https://doi.org/10.5194/acp-10-1369-2010, 2010.

Jensen, E. J., Diskin, G., Lawson, R. P., Lance, S., Bui, T. P., Hlavka, D., McGill, M., Pfister, L., Toon, O. B., and Gao, R.: Ice nucleation and dehydration in the Tropical Tropopause Layer, P. Natl. Acad. Sci. USA, 110, 2041-2046, https://doi.org/10.1073/pnas.1217104110, 2013.

Johnson, A., Lasher-Trapp, S., Bansemer, A., Ulanowski, Z., and Heymsfield, A. J.: Difficulties in Early Ice Detection with the Small Ice Detector-2 HIAPER (SID-2H) in Maritime Cumuli, J. Atmos. Ocean. Tech., 31, 1263-1275, https://doi.org/10.1175/JTECH-D-13-00079.1, 2014.

Johnson, B., Turnbull, K., Brown, P., Burgess, R., Dorsey, J., Baran, A. J., Webster, H., Haywood, J., Cotton, R., Ulanowski, Z., Hesse, E., Woolley, A., and Rosenberg, P.: In situ observations of volcanic ash clouds from the FAAM aircraft during the eruption of Eyjafjallajökull in 2010, J. Geophys. Res.-Atmos., 117, D00U24, https://doi.org/10.1029/2011JD016760, 2012.

Jones, H. M., Haywood, J., Marenco, F., O’Sullivan, D., Meyer, J., Thorpe, R., Gallagher, M. W., Krämer, M., Bower, K. N., Rädel, G., Rap, A., Woolley, A., Forster, P., and Coe, H.: A methodology for in-situ and remote sensing of microphysical and radiative properties of contrails as they evolve into cirrus, Atmos. Chem. Phys., 12, 8157-8175, https://doi.org/10.5194/acp12-8157-2012, 2012. 
Kirkby, J., Curtius, J., Almeida, J., Dunne, E., Duplissy, J., Ehrhart, S., Franchin, A., Gagne, S., Ickes, L., Kürten, A., Kupc, A., Metzger, A., Riccobono, F., Rondo, L., Schobesberger, S., Tsagkogeorgas, G., Wimmer, D., Amorim, A., Bianchi, F., Breitenlechner, M., David, A., Dommen, J., Downard, A., Ehn, M., Flagan, R. C., Haider, S., Hansel, A., Hauser, D., Jud, W., Junninen, H., Kreissl, F., Kvashin, A., Laaksonen, A., Lehtipalo, K., Lima, J., Lovejoy, E. R., Makhmutov, V., Mathot, S., Mikkilä, J., Minginette, P., Mogo, S., Nieminen, T., Onnela, A., Pereira, P., Petäjä, T., Schnitzhofer, R., Seinfeld, J. H., Sipilä, M., Stozhkov, Y., Stratmann, F., Tomé, A., Vanhanen, J., Viisanen, Y., Vrtala, A., Wagner, P. E., Walther, H., Weingartner, E., Wex, H., Winkler, P. M., Carslaw, K. E., Worsnop, D. R., Baltensperger, U., and Kulmala, M.: Role of sulphuric acid, ammonia and galactic cosmic rays in atmospheric aerosol nucleation, Nature, 476, 429-433, 2011.

Korolev, A. and Isaac, G.: Phase transformation of mixedphase clouds, Q. J. Roy. Meteor. Soc., 129, 19-38, https://doi.org/10.1256/qj.01.203, 2003a.

Korolev, A. and Isaac, G.: Roundness and Aspect Ratio of Particles in Ice Clouds, J. Atmos. Sci., 60, 1795-1808, https://doi.org/10.1175/15200469(2003)060<1795:RAAROP>2.0.CO;2, $2003 \mathrm{~b}$.

Korolev, A. V., Isaac, G. A., Cober, S. G., Strapp, J. W., and Hallett, J.: Microphysical characterization of mixedphase clouds, Q. J. Roy. Meteor. Soc., 129, 39-65, https://doi.org/10.1256/qj.01.204, 2003.

Krämer, M., Rolf, C., Luebke, A., Afchine, A., Spelten, N., Costa, A., Meyer, J., Zöger, M., Smith, J., Herman, R. L., Buchholz, B., Ebert, V., Baumgardner, D., Borrmann, S., Klingebiel, M., and Avallone, L.: A microphysics guide to cirrus clouds - Part 1: Cirrus types, Atmos. Chem. Phys., 16, 3463-3483, https://doi.org/10.5194/acp-16-3463-2016, 2016.

Lance, S.: Coincidence Errors in a Cloud Droplet Probe (CDP) and a Cloud and Aerosol Spectrometer (CAS), and the Improved Performance of a Modified CDP, J. Atmos. Ocean. Tech., 29, 15321541, https://doi.org/10.1175/JTECH-D-11-00208.1, 2012.

Lawson, R. P., Heymsfield, A. J., Aulenbach, S. M., and Jensen, T. L.: Shapes, sizes and light scattering properties of ice crystals in cirrus and a persistent contrail during SUCCESS, Geophys. Res. Lett., 25, 1331-1334, https://doi.org/10.1029/98GL00241, 1998.

Lawson, R. P., Baker, B. A., Schmitt, C. G., and Jensen, T. L.: An overview of microphysical properties of Arctic clouds observed in May and July during FIRE ACE, J. Geophys. Res., 106, 14989-15014, 2001.

Lawson, R. P., Baker, B., Pilson, B., and Mo, Q.: In Situ Observations of the Microphysical Properties of Wave, Cirrus, and Anvil Clouds. Part II: Cirrus Clouds, J. Atmos. Sci., 63, 3186-3203, https://doi.org/10.1175/JAS3803.1, 2006a.

Lawson, R. P., Baker, B. A., Zmarzly, P., O'Connor, D., Mo, Q., Gayet, J.-F., and Shcherbakov, V.: Microphysical and Optical Properties of Atmospheric Ice Crystals at South Pole Station, J. Appl. Meteorol. Clim., 45, 1505-1524, https://doi.org/10.1175/JAM2421.1, 2006b.

Lawson, R. P., O'Connor, D., Zmarzly, P., Weaver, K., Baker, B., Mo, Q., and Jonsson, H.: The 2D-S (Stereo) Probe: Design and Preliminary Tests of a New Airborne, High-Speed, HighResolution Particle Imaging Probe, J. Atmos. Ocean. Tech., 23, 1462-1477, https://doi.org/10.1175/JTECH1927.1, 2006c.
Lindqvist, H., Muinonen, K., Nousiainen, T., Um, J., McFarquhar, G. M., Haapanala, P., Makkonen, R., and Hakkarainen, H.: Ice-cloud particle habit classification using principal components, J. Geophys. Res., 117, D16206, https://doi.org/10.1029/2012JD017573, 2012.

Luebke, A. E., Afchine, A., Costa, A., Grooß, J.-U., Meyer, J., Rolf, C., Spelten, N., Avallone, L. M., Baumgardner, D., and Krämer, M.: The origin of midlatitude ice clouds and the resulting influence on their microphysical properties, Atmos. Chem. Phys., 16, 5793-5809, https://doi.org/10.5194/acp-16-5793-2016, 2016.

Lynch, D. K.: Cirrus, Oxford University Press, Oxford, UK, 2001.

Möhler, O., Field, P. R., Connolly, P., Benz, S., Saathoff, H., Schnaiter, M., Wagner, R., Cotton, R., Krämer, M., Mangold, A., and Heymsfield, A. J.: Efficiency of the deposition mode ice nucleation on mineral dust particles, Atmos. Chem. Phys., 6, 30073021, https://doi.org/10.5194/acp-6-3007-2006, 2006.

Nelson, J.: Sublimation of Ice Crystals, J. Atmos. Sci., 55, 910-919, 1998.

Nichman, L., Fuchs, C., Järvinen, E., Ignatius, K., Höppel, N. F., Dias, A., Heinritzi, M., Simon, M., Tröstl, J., Wagner, A. C., Wagner, R., Williamson, C., Yan, C., Connolly, P. J., Dorsey, J. R., Duplissy, J., Ehrhart, S., Frege, C., Gordon, H., Hoyle, C. R., Kristensen, T. B., Steiner, G., McPherson Donahue, N., Flagan, R., Gallagher, M. W., Kirkby, J., Möhler, O., Saathoff, H., Schnaiter, M., Stratmann, F., and Tomé, A.: Phase transition observations and discrimination of small cloud particles by light polarization in expansion chamber experiments, Atmos. Chem. Phys., 16, 3651-3664, https://doi.org/10.5194/acp16-3651-2016, 2016.

O'Shea, S. J., Choularton, T. W., Lloyd, G., Crosier, J., Bower, K. N., Gallagher, M., Abel, S. J., Cotton, R. J., Brown, P. R. A., Fugal, J. P., Schlenczek, O., Borrmann, S., and Pickering, J. C.: Airborne observations of the microphysical structure of two contrasting cirrus clouds, J. Geophys. Res.-Atmos., 121, 13510 13536, https://doi.org/10.1002/2016JD025278, 2016.

Petzold, A., Esselborn, M., Weinzierl, B., Ehret, G., Ansmann, A., Müller, D., Donovan, D., van Zadelhoff, G.-J., Berthier, S., Wiegner, M., Gasteiger, J., Buras, R., Mayer, B., Lajas, D., and Wehr, T.: ICAROHS inter-comparison of aerosol retrievals and observational requirements for multi-wavelength HSRL systems, in: Proceedings of the ESA Living Planet Symposium, Bergen, Norway, ESA SP-686, December 2010, edited by: Lacoste-Francis, H., ESA Communications published and distributed by: ESA Communications, ESTEC, Noordwijk, the Netherlands, p. 102, 2010.

Pruppacher, H. R. and Klett, J. D.: Microphysics of clouds and precipitation, Springer, Berlin, https://doi.org/10.1007/978-0-30648100-0, 2010.

Ray, M. and Anderson, K.: Analysis of flight test results of the optical ice detector, SAE International Journal of Aerospace, 8, 1-8, https://doi.org/10.4271/2015-01-2106, 2015.

Rosenfeld, D. and Woodley, W. L.: Deep convective clouds with sustained supercooled liquid water down to $-37.5^{\circ} \mathrm{C}$, Nature, 405, 440-442, 2000.

Sachweh, B., Barthel, H., Polke, R., Umhauer, H., and Büttner, H.: Particle shape and structure analysis from the spatial intensity pattern of scattered light using different measuring devices, J. Aerosol Sci., 30, 1257-1270, https://doi.org/10.1016/S00218502(99)00045-2, 1999. 
Schnaiter, M., Büttner, S., Möhler, O., Skrotzki, J., Vragel, M., and Wagner, R.: Influence of particle size and shape on the backscattering linear depolarisation ratio of small ice crystals - cloud chamber measurements in the context of contrail and cirrus microphysics, Atmos. Chem. Phys., 12, 10465-10484, https://doi.org/10.5194/acp-12-10465-2012, 2012.

Schnaiter, M., Järvinen, E., Vochezer, P., Abdelmonem, A., Wagner, R., Jourdan, O., Mioche, G., Shcherbakov, V. N., Schmitt, C. G., Tricoli, U., Ulanowski, Z., and Heymsfield, A. J.: Cloud chamber experiments on the origin of ice crystal complexity in cirrus clouds, Atmos. Chem. Phys., 16, 5091-5110, https://doi.org/10.5194/acp-16-5091-2016, 2016.

Stith, J. L., Avallone, L. M., Bansemer, A., Basarab, B., Dorsi, S. W., Fuchs, B., Lawson, R. P., Rogers, D. C., Rutledge, S., and Toohey, D. W.: Ice particles in the upper anvil regions of midlatitude continental thunderstorms: the case for frozen-drop aggregates, Atmos. Chem. Phys., 14, 1973-1985, https://doi.org/10.5194/acp-14-1973-2014, 2014.

Stordal, F., Myhre, G., Stordal, E. J. G., Rossow, W. B., Lee, D. S., Arlander, D. W., and Svendby, T.: Is there a trend in cirrus cloud cover due to aircraft traffic?, Atmos. Chem. Phys., 5, 2155-2162, https://doi.org/10.5194/acp-5-2155-2005, 2005.

Taylor, J. W., Choularton, T. W., Blyth, A. M., Liu, Z., Bower, K. N., Crosier, J., Gallagher, M. W., Williams, P. I., Dorsey, J. R., Flynn, M. J., Bennett, L. J., Huang, Y., French, J., Korolev, A., and Brown, P. R. A.: Observations of cloud microphysics and ice formation during COPE, Atmos. Chem. Phys., 16, 799-826, https://doi.org/10.5194/acp-16-799-2016, 2016.

Um, J. and McFarquhar, G. M.: Single-scattering properties of aggregates of plates, Q. J. Roy. Meteor. Soc., 135, 291-304, 2009.

Vochezer, P., Järvinen, E., Wagner, R., Kupiszewski, P., Leisner, T., and Schnaiter, M.: In situ characterization of mixed phase clouds using the Small Ice Detector and the Particle Phase Discriminator, Atmos. Meas. Tech., 9, 159-177, https://doi.org/10.5194/amt-9-159-2016, 2016.
Voigt, C., Schumann, U., Minikin, A., Abdelmonem, A., Afchine, A., Borrmann, S., Boettcher, M., Buchholz, B., Bugliaro, L., Costa, A., Curtius, J., Dollner, M., Dörnbrack, A., Dreiling, V., Ebert, V., Ehrlich, A., Fix, A., Forster, L., Frank, F., Fütterer, D., Giez, A., Graf, K., Grooß, J.-U., Groß, S., Heimerl, K., Heinold, B., Hüneke, T., Järvinen, E., Jurkat, T., Kaufmann, S., Kenntner, M., Klingebiel, M., Klimach, T., Kohl, R., Krämer, M., Krisna, T. C., Luebke, A., Mayer, B., Mertes, S., Molleker, S., Petzold, A., Pfeilsticker, K., Port, M., Rapp, M., Reutter, P., Rolf, C., Rose, D., Sauer, D., Schäfler, A., Schlage, R., Schnaiter, M., Schneider, J., Spelten, N., Spichtinger, P., Stock, P., Walser, A., Weigel, R., Weinzierl, B., Wendisch, M., Werner, F., Wernli, H., Wirth, M., Zahn, A., Ziereis, H., and Zöger, M.: ML-CIRRUS: The Airborne Experiment on Natural Cirrus and Contrail Cirrus with the High-Altitude Long-Range Research Aircraft HALO, B. Am. Meteorol. Soc., 98, 271-288, https://doi.org/10.1175/bams-d-1500213.1, 2017.

Wagner, R., Benz, S., Bunz, H., Möhler, O., Saathoff, H., Schnaiter, M., Leisner, T., and Ebert, V.: Infrared optical constants of highly diluted sulfuric acid solution droplets at cirrus temperatures, J. Phys. Chem. A, 112, 11661-11676, 2008.

Wallace, J. M. and Hobbs, P. V.: 6 - Cloud Microphysics, in: Atmospheric Science, 2nd Edn., Academic Press, San Diego, 209-269, 2006.

Wendisch, M. and Brenguier, J.-L.: Airborne Measurements for Environmental Research: Methods and Instruments, John Wiley \& Sons, New Jersey, USA, 2013.

Zhang, C. and Harrington, J. Y.: The Effects of Surface Kinetics on Crystal Growth and Homogeneous Freezing in Parcel Simulations of Cirrus, J. Atmos. Sci., 72, 2929-2946, https://doi.org/10.1175/JAS-D-14-0285.1, 2015. 